Article

\title{
Monitoring Moisture Performance of Cross-Laminated Timber Building Elements during Construction
}

\author{
Evan Schmidt and Mariapaola Riggio * \\ Wood Science and Engineering Department, College of Forestry, Oregon State University, Corvallis, OR 97331, \\ USA; evan.schmidt@oregonstate.edu \\ * Correspondence: mariapaola.riggio@oregonstate.edu; Tel.: +1-541-737-2138
}

Received: 9 May 2019; Accepted: 10 June 2019; Published: 14 June 2019

check for updates

\begin{abstract}
There are currently no standards regulating water management for mass timber elements during construction, little knowledge of impacts of moisture exposure (wetting and drying performance, dimensional stability, checking), and few precedents serving as guidelines for monitoring moisture response of mass timber. To address these gaps, a hygrothermal monitoring study was devised to track moisture performance of U.S. made cross laminated timber (CLT) and glulam at a three-story mass timber building. This paper discusses moisture measurements that were collected during the first six months of construction at a CLT rocking shear wall and a timber floor connection. Despite the limited number of structural systems monitored during construction, the distribution and number of sensors in these elements allow to draw some important conclusions. The data confirmed that moisture distribution and wetting/drying rates varied based on local conditions and details (aspect, coatings, connections, etc.), with measurements at an uncoated, north-facing area showing the highest moisture levels (reaching fiber saturation at multiple ply depths and locations). Most locations rarely exceeded 16\% moisture content for more than a few months. Certain moisture-trapping details consistently showed higher moisture levels (i.e., above 16\%) and poorer drying. Some interior plies continued to show slow increases in MC even after months of drying conditions. These observations suggest preventative approaches implementable in the design (e.g., avoiding moisture trapping details), during fabrication (e.g., localized coating), and construction (e.g., sequencing installation to minimize exposure and allow drying).
\end{abstract}

Keywords: mass timber buildings; moisture performance; cross-laminated timber; CLT; hygrothermal monitoring

\section{Introduction}

In North America there has been a recent surge of interest and investment in advancing the use of mass timber construction at the mid- to high-rise scale [1]. Although engineered wood products, such as glued laminated (glulam) and cross laminated timber (CLT) are not novel materials, the building systems, construction practices, and site contexts in which they are being employed sometimes are. While mass timber construction shows a high potential for the rapid erection of structural elements, enclosure is not guaranteed to occur as quickly and, therefore, on-site exposure of timber elements can vary, typically depending on the construction system adopted, (see e.g., [2]). While standards have been developed in certain countries for the on-site protection of timbers during construction and in service (e.g., [3,4]), they are as of yet unmanifested in North American practice, where instead there are only suggested guidelines for such matters [5]. This means that exposure severity will be, in large part, defined by designer/contractor precautions-which will be influenced by awareness of the issue and possible solutions-in addition to the construction system, schedule and site conditions themselves. 
Short-term wetting or high relative humidity (RH ranging between $80 \%$ and $95 \%$ [6]) can lead to colonization by mold fungi. Mold damage can be cleaned, but moisture sources should be identified and removed to avoid damage recurrence. Under persistent conditions of direct exposure and/or moisture trapping, wood can reach fiber saturation ( $>28 \%$, depending on wooden species), at which point it becomes a conducive habitat for decay fungi that can, over time, reduce its structural capacity and render it unserviceable [6].

Comprehensive research has been done on mold and decay growth [7-9] in different exposure conditions to support performance-based service life design. Few studies, however, have explored the implications of moisture exposure of mass timber during construction or for accidental wetting in service e.g., [10,11]. Checking, interfacial shearing/delamination, and warpage-all observed on CLT exposed to environmental simulations within a laboratory [10-12] and in computer simulations [13]-are examples of moisture-induced damage that can occur as a result of heavy environmental fluctuations, particularly when involving direct exposure to liquid water. Moisture induced discontinuities, which can form already during construction, can affect various physical and mechanical properties. For instance, according to Gülzow et al. [10] checking of CLT lamellas can cause a reduction of the modulus of elasticity (MoE) perpendicular to the grain; Schmidt et al [11] observed a modulus of rupture (MoR) reduction of short-span CLT panels due to the effects of checks on rolling shear. Moisture-induced discontinuities occur at any depth within a panel [14] but they are typically most pronounced at the edges and connections where risk of moisture fluctuation and accumulation are the greatest [15].

Structural timbers subject to high constant loads in an un-steady environment and with high moisture contents can experience differed deformations due to the combination of mechano-sorptive, creep and shrinkage-related strain [16,17]. The effect of these phenomena on the performance of innovative timber systems, such as post-tensioned frames and shear walls, is a research area still in development $[18,19]$.

One strategy to assess the hygrothermal performance of a timber structure, i.e., the response of timber components to environmental loading, is to permanently instrument it with sensors that monitor environment and wood moisture content (MC). It is worth noting that moisture content and environmental conditions have a critical role on the performance of several construction systems and materials other than wood (see for instance, [20-23]). Therefore, hygrothermal monitoring of different moisture-sensitive materials can be required in a building, and for each material/product the most suitable measurement technique should be selected, considering material-specific features, moisture response, and potential effects on short- and long-term performance of the structure.

This paper, which focuses specifically on the early stages of implementation of a hygrothermal monitoring study of the Forest Science Complex at Oregon State University, has three primary aims: (1) to share observations of the hygrothermal performance at a few critical locations during construction; (2) to illuminate the monitoring methodology and discuss future improvements; (3) to disseminate results that are practicable to the mass timber industry.

In Europe, structural and hygrothermal monitoring of mass timber structures has focused primarily on assessing glue laminated timber members in various service classes, e.g., [14,24-27], which are defined by anticipated in-service moisture levels. The first hygrothermal monitoring study of a CLT structure was reported by Jorge [28], though only a few points were measured and only a few months of data were reported. At the House of Natural Resources at the Swiss Federal Institute of Technology (ETH) in Zurich, a monitoring study [29], started during construction in 2014, includes direct hygrothermal monitoring of CLT roof panels. At ETH, a protective canopy was built to envelope the structure throughout its erection, and the monitored CLT panels never exceeded $11 \% \mathrm{MC}$. The Wood Innovation and Design Centre in Prince George, North British Columbia—erected starting spring of 2014-has shown similarly low/stable CLT MCs from about 13\% during construction to about $11 \%$ in-service, though with only five locations monitored [30]. 
While a handful of structural health monitoring (SHM) projects of mass timber structures have begun more recently in North America, monitoring at Brock Commons (Vancouver, British Columbia) [31,32] and Carbon12 (Portland, Oregon) [33,34], are the only available studies that have expanded the hygrothermal component to a large-scale analysis of mass timber (particularly CLT) exposed to rain during construction. As an example of magnitude, Brock Commons (18 stories) has over 300 sensors installed (192 MC sensors in CLT), while Carbon12 (eight stories) has 82 MC sensors (43 in CLT). These studies are also paralleled by a growing body of environmental laboratory simulations and modeling efforts, aiming at assessing the wetting- and drying-performance of CLT in various exposure, sealant, and assembly schemes [11,12,33,35-39]. Research focusing specifically on overhead wetting of larger CLT specimens $[11,12,33,37,39]$ have varying conditions, results, and insights, but generally have one common observation: CLT, even when heavily wetted, is capable of drying to acceptable MCs (e.g., $<16 \%$ ) in less than a half year (and in many cases less), except where certain moisture trapping conditions prevail (e.g., addition of floor/wall assembly layers such as impermeable/semi-permeable membranes and a concrete screed, wood-on-wood connections, etc.). Data from the SHM study at Brock Commons-which began construction summer of 2016-showed that after one year the vast majority of floors-which were topped with a concrete screed-were in-between 16\%-20\% MC (averaging about 16\%), and after the second year the majority of these had dried to below 16\% (averaging about 13\%) [32]. These data show that drying in floor locations was slow after the concrete screed and respective assemblies were installed. Factors at Brock Commons that favored hygrothermal performance included erection in summer, high level of standardization and prefabrication, which included the installation of the façade coincident with erection of framing, self-sheltering of floors, the use of wax at end grain/hardware cut-outs, and the application of a vapor-permeable coating on all CLT surfaces [27].

Carbon12 was erected in winter during record rainfalls in Portland [33], and many sensors installed in cut-outs of the CLT floors were damaged by ponding water [33,34]. The data from sensors that maintained readings, however, were corroborated with laboratory experiments and hygrothermal simulations, and suggest three critical points about CLT moisture performance:

(1) Floor elements erected earlier in construction showed much higher MC gain and longer periods of time spent above the fiber saturation point, than the roof erected later;

(2) In CLT floors, while the upper-most plies showed the most gains, all ply depths showed some MC vulnerability, with much slower drying rates at the interior layers;

(3) Similar building member types tended to display high variability relative to one another in MC gain and loss.

The variability of hygrothermal performance observable between locations within a given structure is also mirrored by variability in performance between monitoring studies themselves. This is attributable to environmental, design, construction and material factors. While the variability between studies illustrates the need for a larger body of monitoring projects (capturing a wider array of conditions), the variability among locations within a study reinforces the need of a dense network of MC sensors-with some redundancy - in order to capture the full spectrum of a structure's performance.

\section{Introduction to the Monitoring Study at the Forest Science Complex}

At the time of writing, the Forest Science Complex (Figure 1) was under construction. This three-story, 10,600 $\mathrm{m}^{2}$ building, designed by Michael Green Architecture, will serve as the new headquarters for the College of Forestry at Oregon State University, in the main campus location,

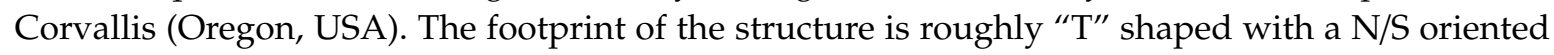
wing, $40 \mathrm{~m}$ long and $18 \mathrm{~m}$ wide (the atrium) that butts into a larger $\mathrm{E} / \mathrm{W}$ wing, $76 \mathrm{~m}$ long and $22 \mathrm{~m}$ wide (the academic wing). The timber structure is comprised of a glulam post-and-beam gravity system, and lateral load-resisting system including hybrid wood/concrete floor diaphragms with CLT decks, and post-tensioned, self-centering, CLT shear walls [40,41]. The flat roof is comprised of CLT panels 
separated from the mass plywood panel (MPP) [42] upper diaphragm by $2.5 \mathrm{~cm}\left(1^{\prime \prime}\right)$ thick plywood strapping (Figure 1b) in the academic wing, and MPP supported directly on deep, long-span glulam beams in the atrium. A moisture mitigation protocol [43] was developed prior to manufacturing the timbers that specified a vapor permeable coating be shop-applied at (1) the edges of all mass timber elements (double-coated), (2) all faces of glue laminated columns and beams, (3) the faces of CLT panels that will be visible in-service, and (4) all hardware cut-outs (double-coated). The façade includes a curtain wall in the atrium and rain-screen assemblies supported either by metal framing or CLT walls. The conventional flat roof assembly is comprised of a vapor retarder, a poly-iso insulation package, cover board, and a roofing membrane.

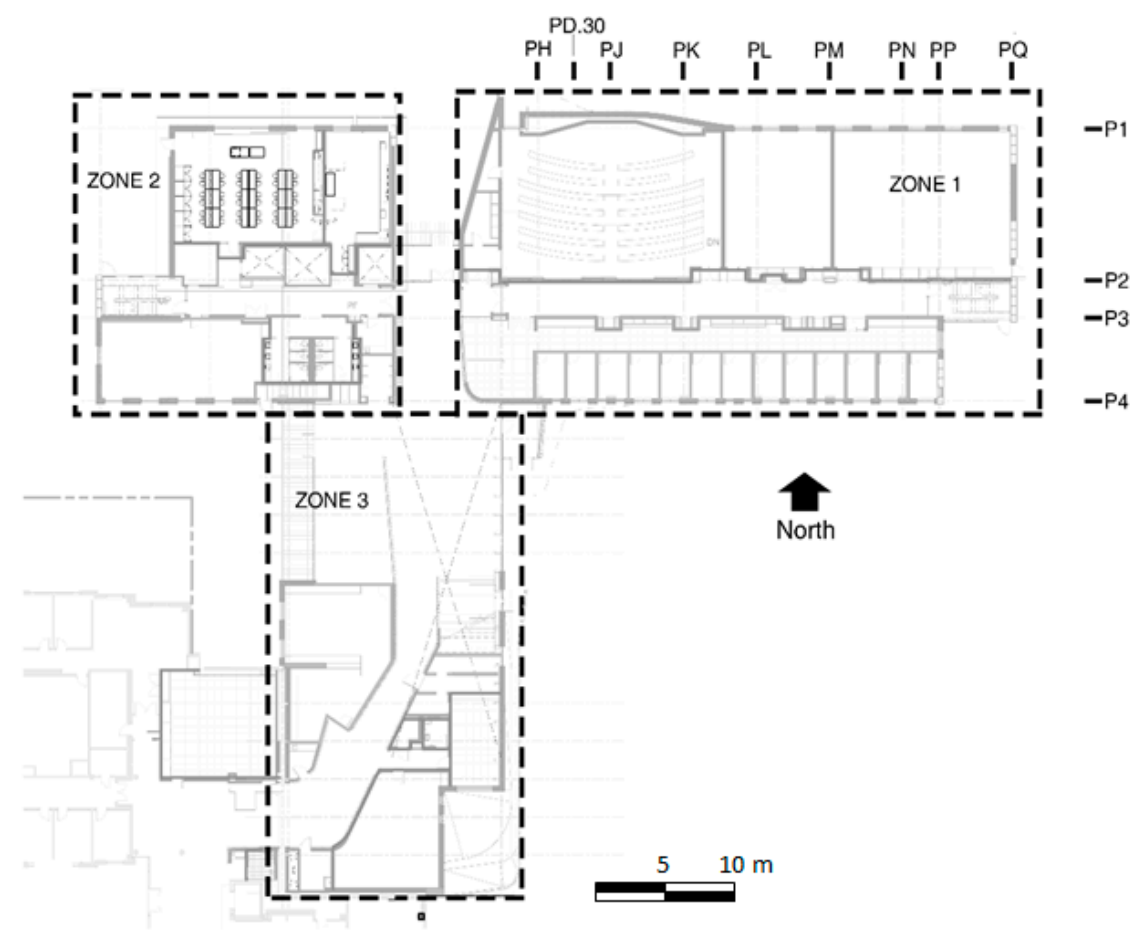

(a)

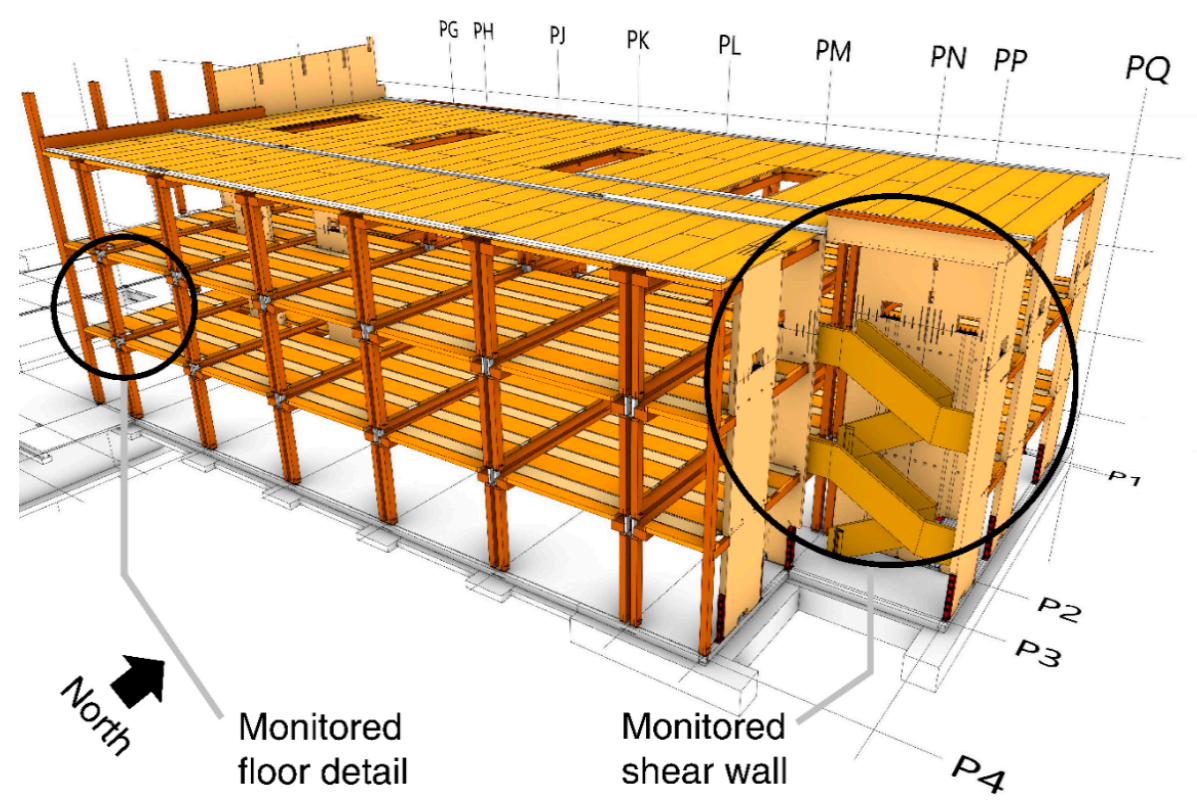

(b)

Figure 1. (a) Plan of the Forest Science Complex and depiction of the construction zones. Image courtesy of Michael Green Architecture. (b) The structural system of Zone 1, with the locations of construction monitoring. Image courtesy of Structurecraft. 
The Forest Science Complex will be the subject of a comprehensive monitoring campaign that will track hygrothermal performance (weather, interior climate, wood moisture content, and heat flux) and structural performance. The structural monitoring component, which is not objective of this paper, will track a series of performance parameters: (1) post-tensioning loss at the four pre-stressed tendons within seven of the highest loaded shear walls; (2) dimensional change and relative displacements in three of the most loaded shear walls; (3) floor deflections along the full height of the building at a single location; (4) the global dynamic behavior of the structure.

\section{Materials and Methods}

\subsection{The Forest Science Complex: Construction Events}

The construction of the building was planned in three phases delimited by spatial "zones," each arranged to be finished sequentially and with some overlap, in order to minimize exposure of the structure (Figure 1a). Framing began on November 302017 in Zone 1 and followed this general sequence: CLT shear walls and floor 1 columns, floors (beams and decks), CLT shear walls' upper sections (doweled in place), frame and floors in level 3, roof, and envelope. Zones 2 and 3 framing were planned to be erected and enclosed following a similar sequence. Timber members arrived in batches and were erected while wrapped, after which they were unsheathed and, in the case of the shear walls, left with an impermeable cap that covered the top edges. The average time for the framing of a floor was about three weeks. The framing of Zone 1 was completed 73 days after the onset of erection, after which another 26 days were taken to complete the weather enclosure of the roof. Enclosure of the south façade was completed in stages over the course of a month. Construction was temporarily stopped from the end of March and the beginning of August 2018, to allow for independent investigations after that manufacturing defects (delamination) were found in some CLT panels. This paper presents data of the first 6 months of construction, which might realistically represent a typical project.

\subsection{Factors Considered When Defining the Locations of Moisture Content Sensors}

The primary factors that influenced the definition of the MC sensor locations in the hygrothermal monitoring plan were (1) the anticipated vulnerability of a location to moisture ingress and/or trapping (both during construction and in-service), (2) the need for a compromise between redundancy and diversity in data (e.g., having comparable locations, while capturing a variety of building, detail, and material conditions), and (3) the need to proximally couple hygrothermal data with other sensor data (i.e., displacements and accelerations), as part of a long term structural health monitoring campaign tracking environment, $\mathrm{MC}$, serviceability and structural performance. Simultaneously, the definition of locations was influenced by the limitations imposed by costs (e.g., number of sensors), technology (e.g., sensor ranges, accessibility) and construction/design considerations (e.g., schedules, installation feasibility, conflicting assembly conditions and services, aesthetics, etc.).

Vulnerability of wood-based structural elements to detrimental effects of moisture stagnation and/or moisture cycling, as those discussed in Section 1, was considered at three scales: (1) building (e.g., by duration of zone exposure, construction schedule, and aspect), (2) assembly/detail (e.g., potential for moisture trapping, detail complexity, waterproofing, and orientation in space), and (3) the material/sub-assembly scale (e.g., wood product type, ply depth, weather sealant, etc.). At the building scale, Zone 1 was identified as the most vulnerable due to its being erected first and during the rainiest part of the year. Since the shear walls and 2nd floor CLT elements were among the first to be installed, these were considered to be highly vulnerable regions during construction. Skylights, roof drains, and proximity to mechanical units and edges were highlighted as critical factors for determining roof locations. Due to prevailing southern winds during winter, the south side of the structure was identified as most vulnerable to wind-driven rain and more pronounced thermal fluctuations, due to the effects of solar radiation. At the assembly scale, the floors were noted as vulnerable to pooling and moisture trapping at the floor-to-floor connection, where the CLT panels' edges rest on glulam beams, 
forming a canal made continuous by plywood bridging. The CLT shear walls were considered at risk for higher wind-driven rain loads and gravity fed leaks in edge openings caused by wane or gaps between boards. The edges and ends of the most exposed shear walls were identified as at risk for wicking and moisture trapping where connected to other members or the concrete stem wall.

At the material/sub-assembly scale, the outer layers (particularly the upper layers of horizontal elements) and the end grain at the panel edges $[11,12,15,39]$ were identified as the most vulnerable to water ingress. Such concern was informed in part by laboratory results that suggested moisture tended to accumulate at the gaps and the interface of the upper two plies of CLT floors after wetting [11] and indications that sealants can at times negatively impact drying [39].

\subsection{Hygrothermal Monitoring Measurements}

Moisture content data were collected using resistance-type sensors with insulated pin shanks inserted at different depths/plies. In addition to periodic (continuous) MC measurements taken from permanently installed sensors, discontinuous MC measurements were made using a handheld meter capable of measuring to a depth of $8.25 \mathrm{~cm}$.

Critical aspects of the moisture sensor installation included (1) avoiding gaps and knots between electrode's pins, (2) using guides for exact pin spacing, (3) drilling holes the exact length of the insulated housing using digital calipers, and drill-stops, (4) ramming in the pins at an equal rate and leaving the base flush with the wood, and (5) ensuring communication with the cloud system. Care was taken to seal the exposed sensor head with silicone in order to avoid condensation or moisture shorting during exposure, as well as to minimize heat conduction through the pins to the wood substrate [44].

Internal temperatures of the SW-oriented shear wall were measured from the north side of the wall in selected locations with thermistors that were bored in and sealed off with silicone, as recommended by [44]. Measurements at all locations were corrected for using the temperature values from the closest approximate thermistor depths.

Weather data at the construction site (temperature, relative humidity, wind speed/direction, and precipitation) were acquired with a weather station installed on the roof of an adjoined structure, Due to observed lack of sensitivity of this weather station to small precipitation events, precipitation data from the weather archives of another station, located $13 \mathrm{~km} \mathrm{NE}$ of the construction site, were also plotted as a further reference [45].

\subsection{Hygrothermal Monitoring Locations}

Two locations were chosen for the MC monitoring of Zone 1 during construction: a CLT shear wall (Figures 1-3) and a CLT floor connection (Figures 1 and 4). The CLT shear wall is located in the Eastern stairwell, is $9.5 \mathrm{~m}$ tall $\times 2.8 \mathrm{~m}$ wide, and sits at the periphery of the structure on an E/W axis. It is comprised of seven layers of $5 \times 20 \mathrm{~cm}$ (nominal), PRG320 V1 grade [46] Douglas Fir (Pseudotsuga menziesii) lumber, bonded using melamine-formaldehyde (MF) resin (non edge-glued). Hardware and notches in the shear walls represent areas of particular concern for water penetration during construction (Figures 2 and 3). The three-story high shear wall is comprised of two sections: splice connections connect the upper section of the wall (ca. $4 \mathrm{~m}$ high) to the lower one (ca. $9 \mathrm{~m}$ high). Four high-strength thread bars are located in a vertical chase and restrained at the top of the lower shear wall section and at the foundation, to provide a post-tensioning reinforcement. U-shaped Flexural Plates (UFP) couple two adjacent shear walls. These dissipaters are also used at the corner hold downs.

The lower shear wall section was one of the first elements to be erected on-site, and was outfitted two days after its installation with two groups of MC sensors: one group at the upper section of the panel and one at the lower section (Figures 2 and 3). A total of six continuous moisture sensors were installed at the upper section of the shear wall and seven continuous moisture sensors were installed at the lower section. Ply 1 represents the southernmost surface ply, facing the interior of the stairwell. Two additional shear wall locations were monitored discontinuously (on day 8), and two more measurement locations were added after 63 days. These additional measurements were taken 
to depict local conditions such as those created by the panel aspect (i.e., $\mathrm{S} / \mathrm{N}$ or $\mathrm{E} / \mathrm{W}$ ), and observed local wicking.

The monitored CLT floor connection is located on the second floor at the southwest edge of Zone 1 (Figure 1). The detail is comprised of 5-ply CLT floor panels that rest on glulam beams with $10 \mathrm{~cm}$ overlap and a plywood spacer in between the two elements (Figure 4). The monitored floor panel was installed on December 182017 (day 18 - counting from the installation of the first shear wall) and was outfitted with MC sensors on January 82018 (day 39). A total of six continuous moisture sensors were installed at the floor connection. Discontinuous, hand-held, measurements (referred to as $\mathrm{HH}$ in this paper) were collected directly above and adjacent to the continuous measurements in the floor, as well as north of the monitored location at a comparable, but fully shaded, CLT floor area.
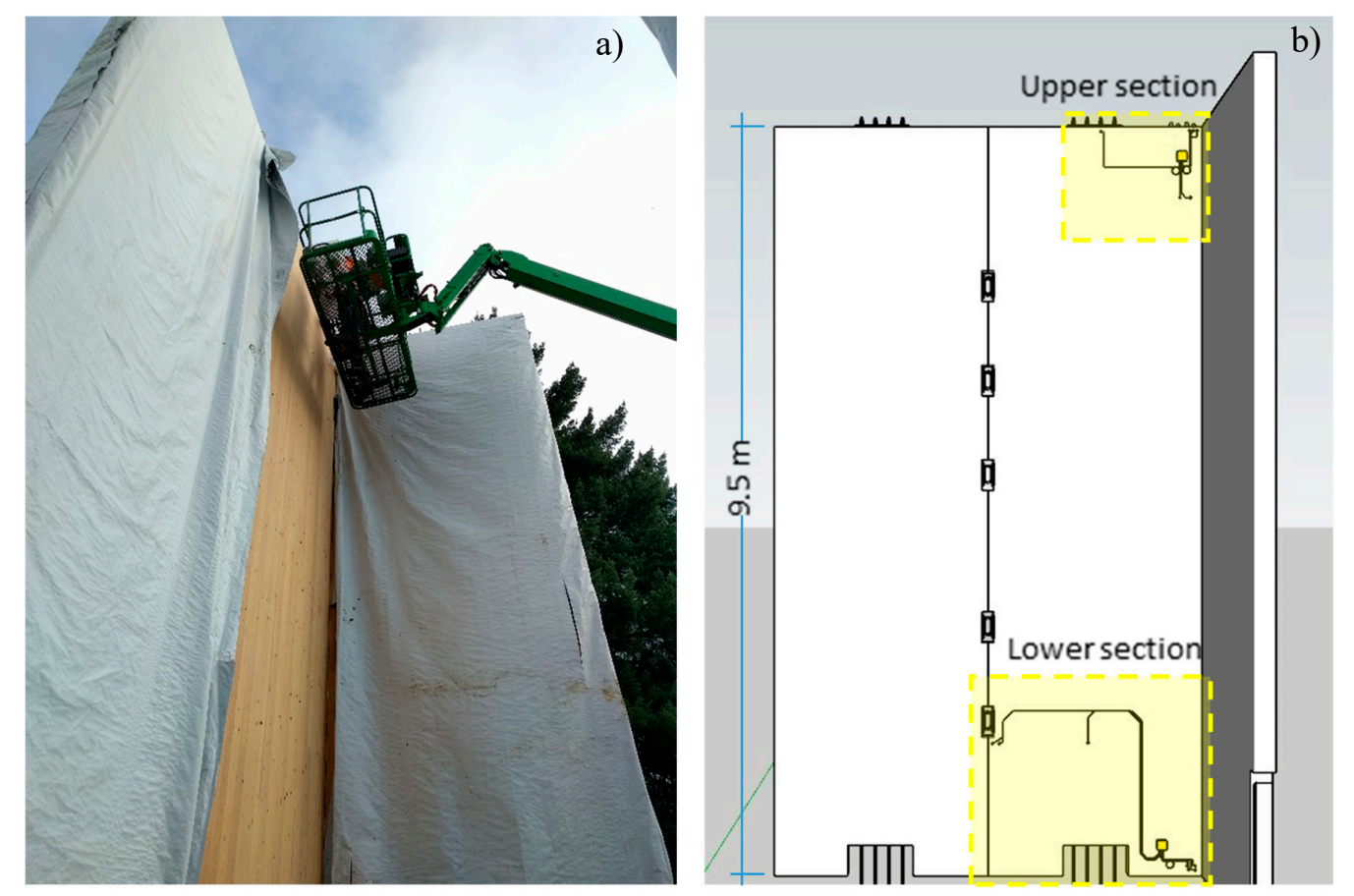

Figure 2. (a) the installation of sensors at the upper section of the shear wall; (b) a graphic of the upper and lower sections of the shear wall with sensors. The red dot on the right-hand panel is a handheld moisture measurement location. 


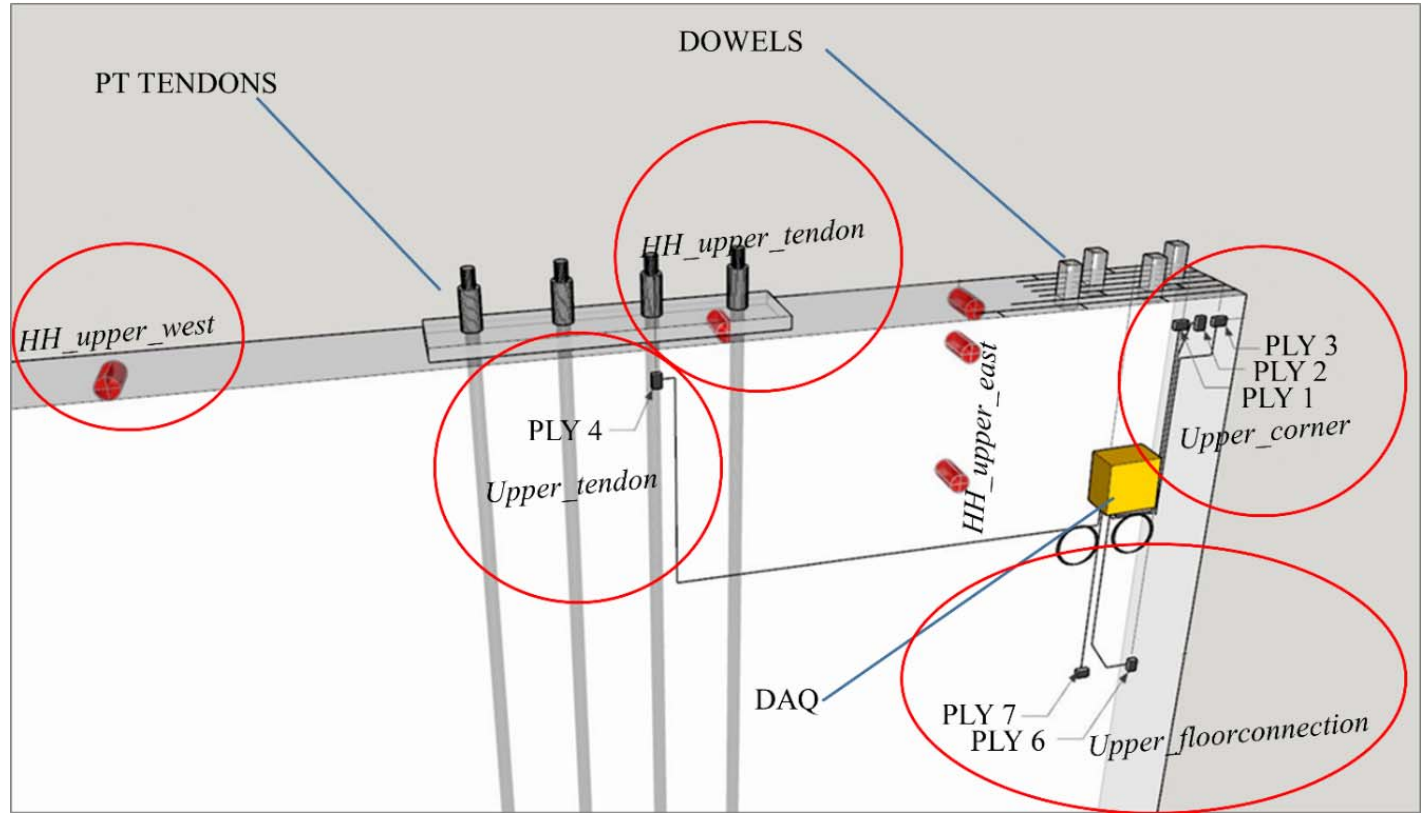

(a)

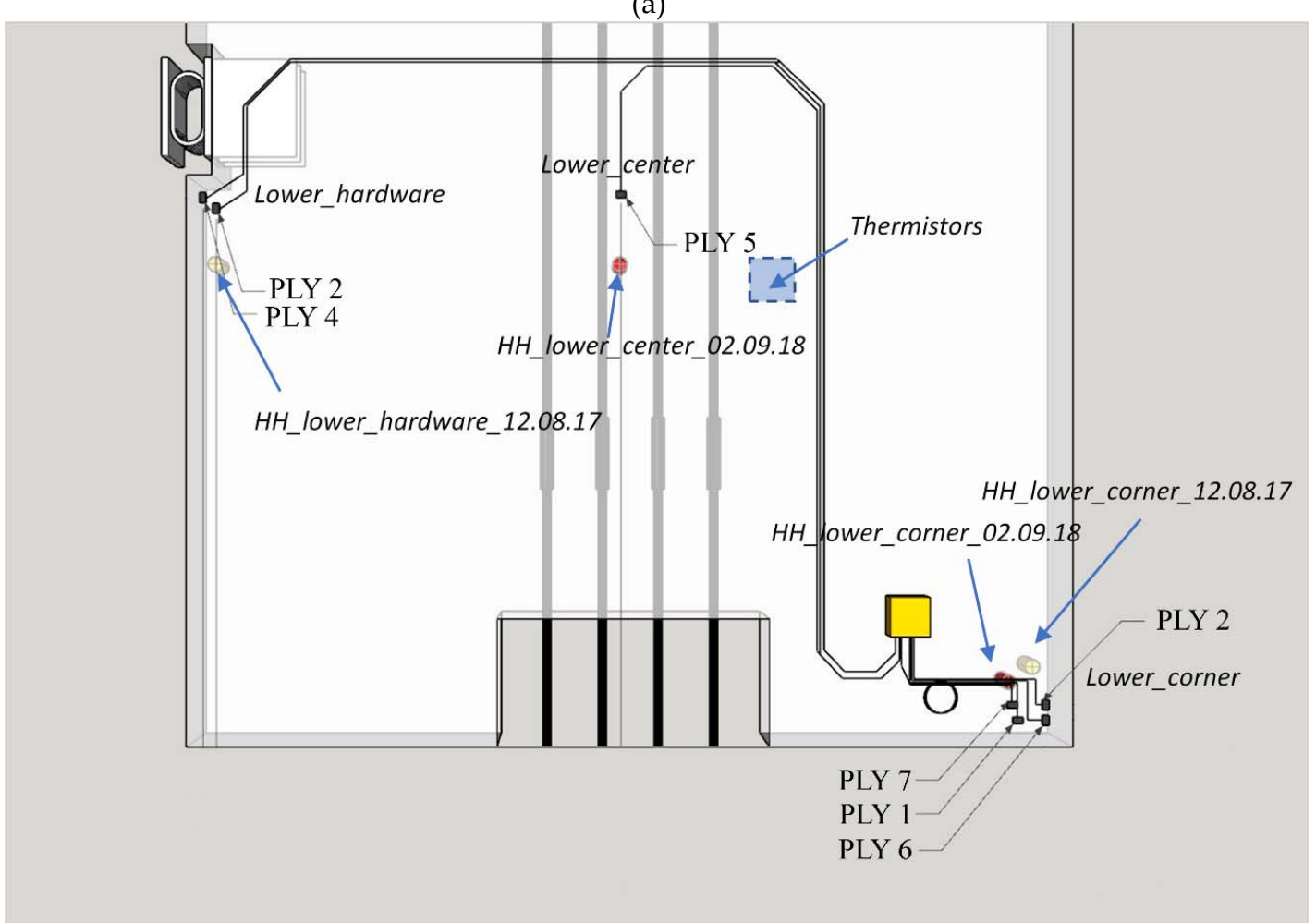

(b)

Figure 3. Details of the upper (a) and lower (b) shear wall sections with MC sensor locations. Discontinuous measurement locations (designated $\mathrm{HH}$ in figures) are depicted by red cylinders. Italicized text denote a sensor group. 


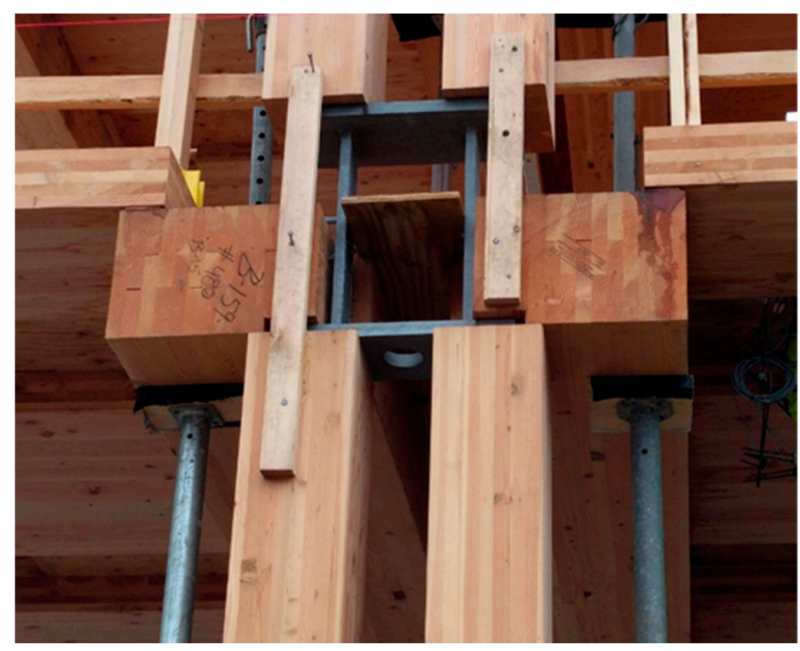

(a)

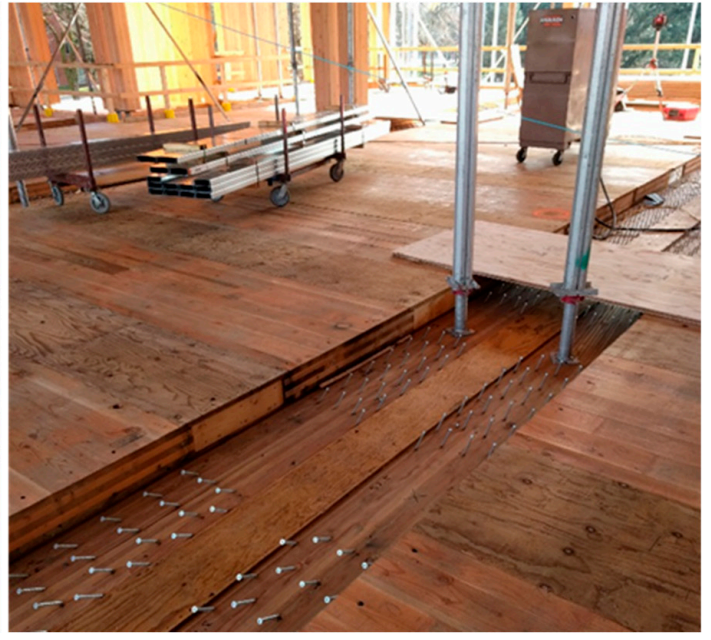

(b)

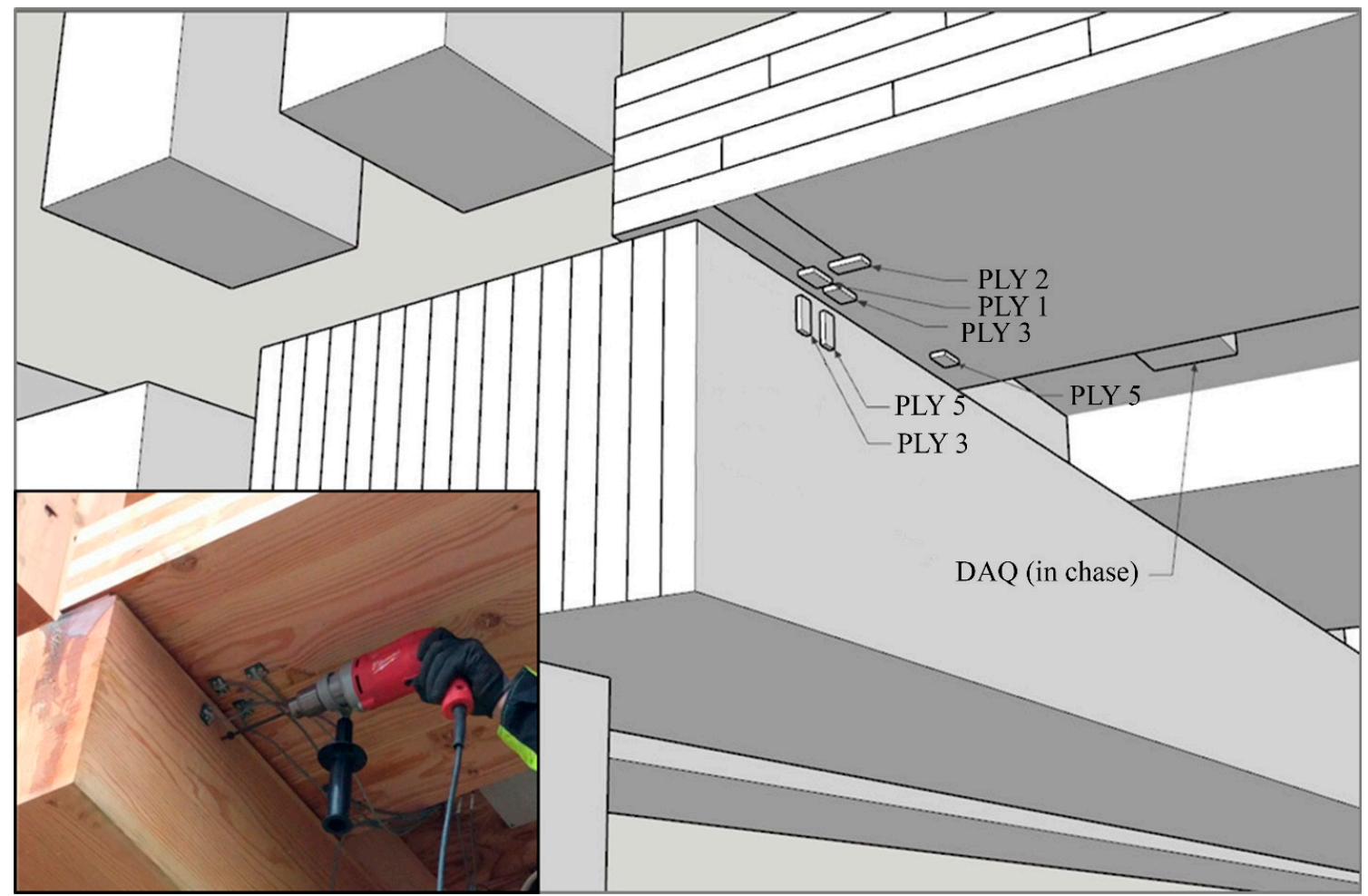

(c)

Figure 4. (a,b) Floor detail chosen for monitoring. (c) MC sensor locations in the floor connection.

\subsection{Post-Processing and Analysis of Moisture Content Data}

Literature provides estimates of uncertainty for resistance-based moisture content measurements due to variability between species and varying moisture contents (e.g. [47,48]). In this study, both continuous and discontinuous readings were corrected for Douglas fir considering the manufacturer's calibration for this species [44], and corrected for temperature using embedded thermistors (continuous readings) and ambient temperature (discontinuous readings). 
Permanently installed sensors used have an approximate measurement range of $8 \%-30 \% \mathrm{MC}$, with a resolution of $0.1 \%$, and a listed accuracy of $+/-1 \%$. The manufacturer's calibration was not verified by comparison against oven-dry tests.

Data collected during a few distinct periods of construction displayed high fluctuations that suggested augmentation of resistance readings by external environmental influences. Previous studies generally highlight the high level of noise and sensitivity that such sensors are prone to, particularly when exposed to outdoor, extreme, or changing environmental conditions (e.g., $[11,14,25,26])$. While lack of proper temperature correction is well understood to systematically offset readings (in the range of about $0.5 \%-1.5 \% \mathrm{MC}$ per $10{ }^{\circ} \mathrm{C}$, depending on temperature, MC and species) [49,50], factors such as electromagnetic interference, internal checking, loss of pin contact with wood, and condensation are more difficult to isolate, and can manifest strong data interference, e.g., rapid gains and losses of large magnitude, step changes, or loss of data transmission all together $[11,15,25,28,33,51]$. While data is almost always presented by researchers raw, a few studies have utilized post-processing techniques such as the omission of erroneous values combined with the application of a moving average [11,14,15]. Niklewski et al. defined erroneous values by the relative deviation of values from the moving average itself-but at times applied judgement to omit larger segments of data, or entire sensors, which appeared to be compromised [15].

The behavior of the MC sensors located at the shear wall during the first 53 days (prior to overhead protection from rain) was consistent with the effects subsequently observed in the laboratory when exposing sensors directly to spray, even when sealed with silicone [11,12]. These effects primarily included unrealistic spikes in the data during periods of rain (from what appears to be shorting of the sensors), and sudden drops during periods of lower humidity, back to what is assumed to be correct reading levels. Although the data from this period is considered too erratic to specifically analyze, it is nonetheless valuable to include because it allows to infer a trend, and serves to familiarize the reader with the visible effects of moisture exposure on sensor readings, for future construction monitoring. Again, this paper focuses the discussion on the data that showed consistency in readings and that were verified with discontinuous measurements. All of the moisture data from this study are presented both raw (with temperature and species corrections) and with eight-day central moving averages. The floor MC graphs-in addition to including raw data and an eight-day moving average-also include a second moving average that omit about one month of data. The data during this period also showed symptoms of sensor shorting by exposure to water (discussed in Section 3.3) caused by pooling of rainwater in the detail and percolation along the installation area nearby.

\section{Results}

\subsection{Weather}

Figure 5 shows climatic data (rain, relative humidity, and temperature) at the construction site as well as precipitation data from the Hyslop Weather Station [45]. Construction key dates during the monitored period are reported along with the weather data in Figure 5. The 2017/2018 winter saw less precipitation than average: while the National Oceanic and Atmospheric Administration (NOAA) listed 100 year norms in the nearby city of Eugene, Oregon ( $65 \mathrm{~km}$ south) at $979 \mathrm{~mm}$ of rainfall between December and May [52], the weather stations at the construction site and Hyslop registered 179 and $554 \mathrm{~mm}$, respectively. Relative humidity and temperature data highlight that February marked a dry and warm period, and that precipitation mostly ceased after day 140 of construction. 


\section{Zone 1 Construction key dates}
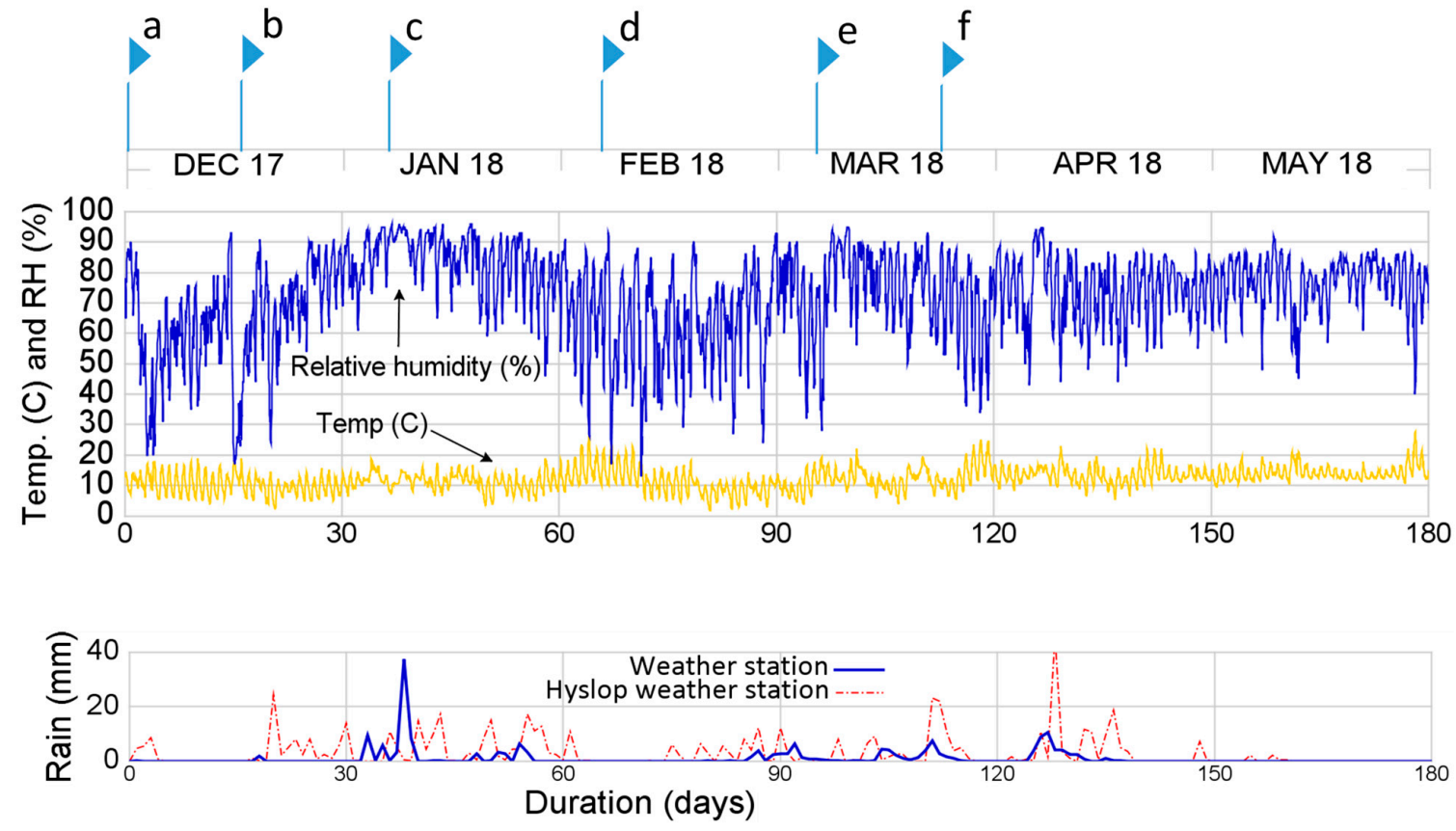

Figure 5. Weather data at the site between December 2017 and May 2018, and (upper) Zone 1 construction key dates: (a) install of shear wall sensors; (b) install of 1st floor; (c) install of floor sensors; (d) roof framing complete; (e) roof weather protection complete; (f) construction shutdown.

\subsection{CLT Shear Wall Moisture Content}

Moisture measurements at Upper_corner_1,2, and 3 showed higher moisture levels in late January (days 50-60, plies 1 and 3 peaking about 18\% and ply 2 peaking about 15\%), quick drying to the 10\%-14\% MC range (over about 2-4 weeks), and slowly decreasing MC levels thereafter (Figure 6-c). Moisture measurements at Upper_floorconnection_6, and 7 (North face) showed wetting and drying during the same periods as the latter sensors, but moisture levels were higher (peaking at about 21\%) and remained higher (plateauing at about 15\%) (Figure 6e,f). Upper_tendon_4 experienced the highest MC increases (>24\%) and also dried more slowly than the others, to about $18 \%$ by May (Figure $6 \mathrm{~d}$ ). 

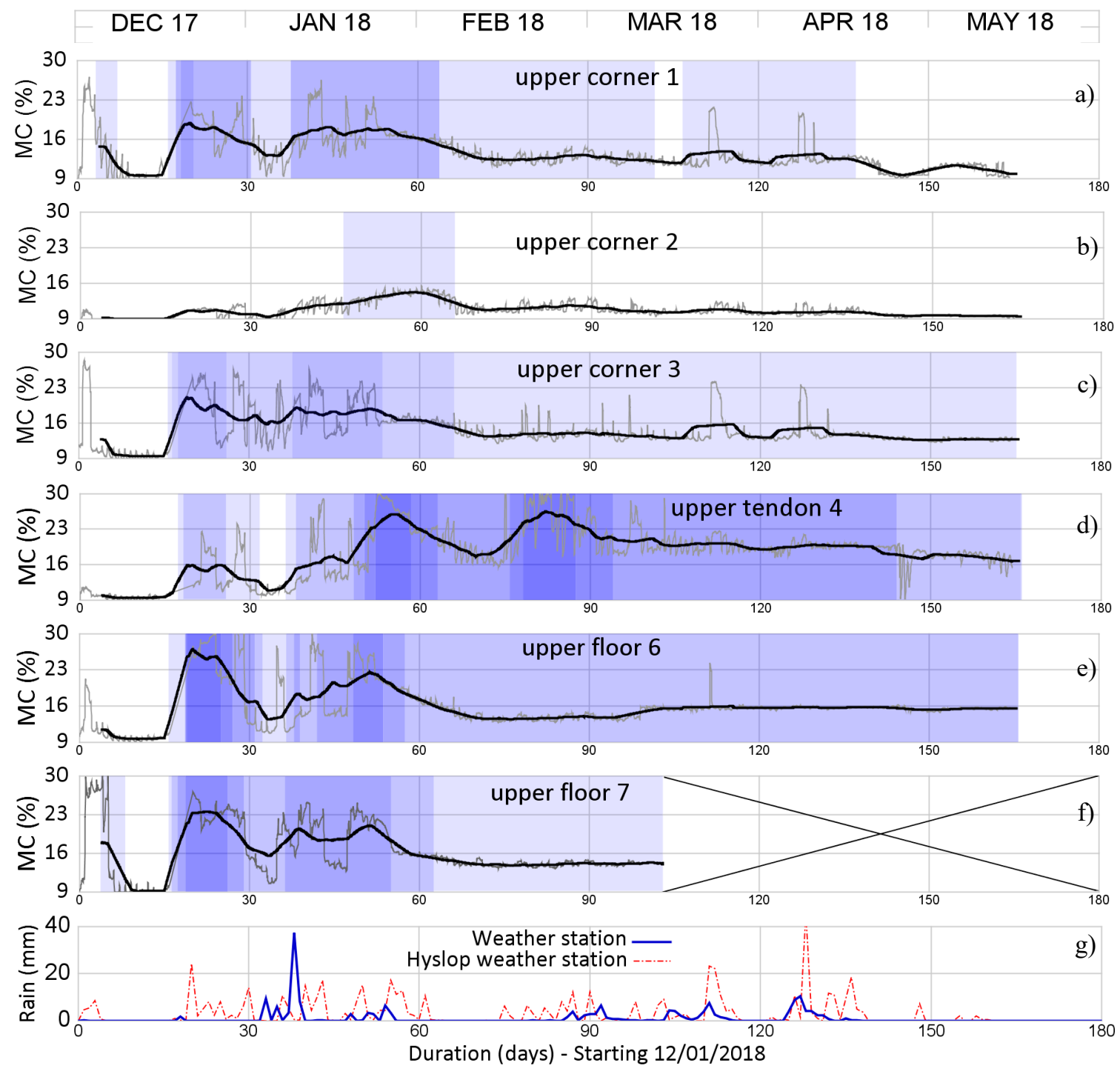

Figure 6. Continuous moisture measurements taken at the upper shear wall. Locations are illustrated in Figure 3a: (a) upper corner ply 1, (b) upper corner ply 2, (c) upper corner ply 3, (d) upper tendon ply 4, (e) upper floor ply 6, and (f) upper floor ply 7. (g) Rainfall data. The first 55 days experienced higher levels of noise due to direct exposure of the sensors. Raw data is plotted in light grey. An eight-day moving average is depicted with a thick black line. The blue shading overlaying the graph represents tiers of MC_-growing deeper in hue at 3\% intervals (with $<12 \%$ MC as white). Upper_floor_7 malfunctioned near day 100 , demarcated by the " $X$ " over the graphic.

Discontinuous measurements taken at HH_upper_3.8 $\mathrm{cm}$ and $14 \mathrm{~cm}$ consistently showed MC values approaching or exceeding the fiber saturation point (Figure 7). When considering all measurements taken at the upper North face, nearly every discontinuous measurement was greater than $16 \%$ (64/75 measurements). Additionally, about half of the measurements were above $20 \%(38 / 75)$, and a fifth (15/75) were approaching or beyond the fiber saturation point (i.e., $>27 \%)$. Measurements at HH_upper_tendon and HH_upper_west, further from the exterior of the structure, registered somewhat lower moisture contents than the east side (together averaging $18 \%$ at ply $7,16 \%$ at ply 6 , and $16 \%$ at ply 5$)$. 


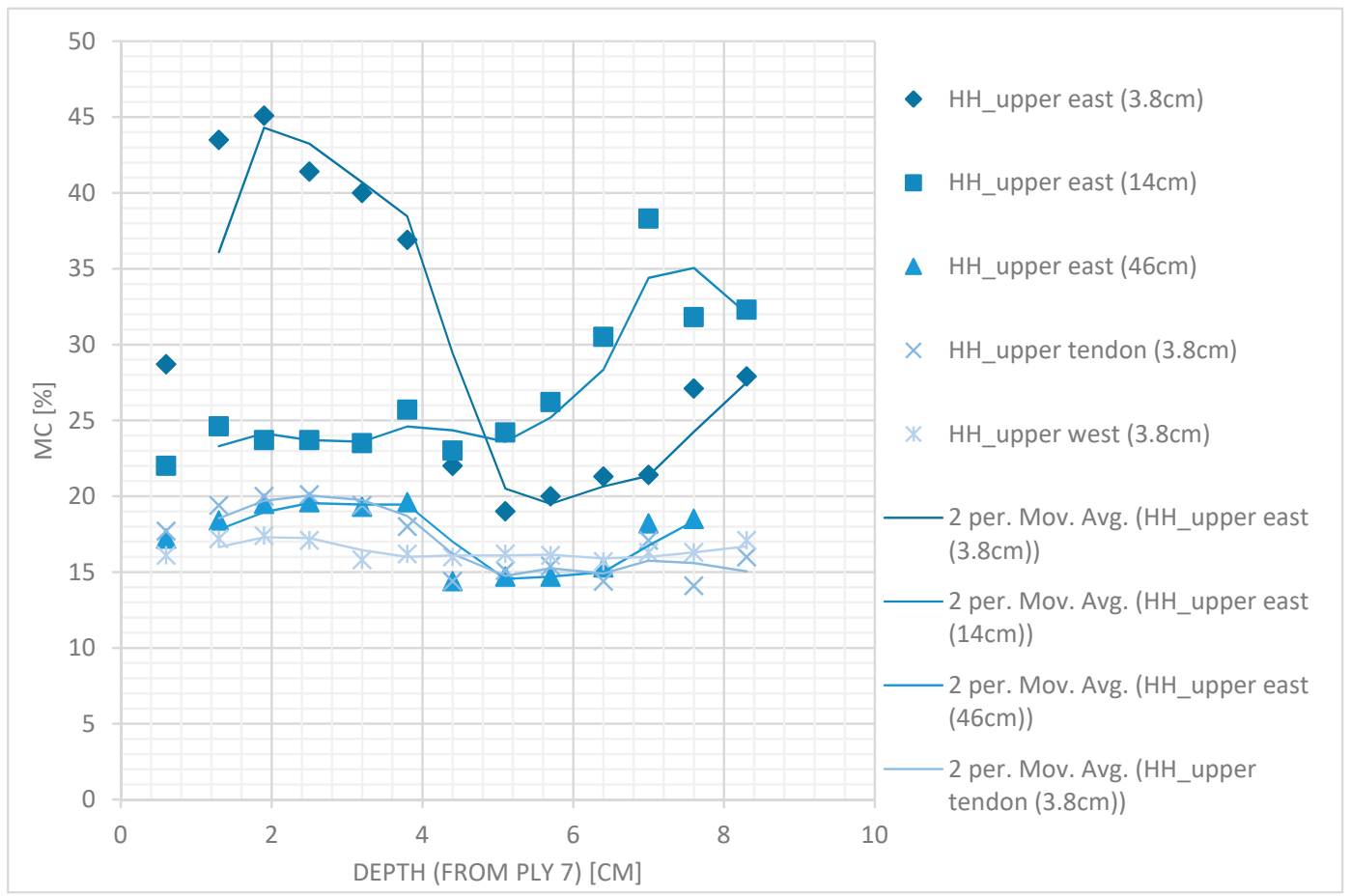

Figure 7. Discontinuous moisture measurements taken at the upper section of the monitored shear wall, from the North face side. Continuous lines are moving averages. Dimensions in the data labels (e.g., "3.8 $\mathrm{cm}^{\prime}$ ) indicate the distance the measurements were taken below the upper edge of the panel, while the depth of measurement shows the gradient of MC readings through the thickness of the panel $(0.6 \mathrm{~cm}$ increments, from ply 7 to ply 5$)$. Locations depicted in Figure 3a. Date of measurements: February 92018.

Continuous moisture measurements at the lower east corner of the shear wall (Lower_corner_1, $2,7)$ showed trends similar to those for the upper corner location, though they generally peaked at slightly higher MCs (18\%-20\%) (Figure 8). Low_hardware_4 showed large and rapid moisture content fluctuations between about $12 \%$ and $21 \%$ that correlated with precipitation and dry spells, suggesting sensor shorting (Figure 8c).

A series of locations (Lower_corner_6, Lower_center_5 and Low_hardware_2) registered a moisture content below the detectable threshold $(\mathrm{MC}<9 \%)$. Considering the unlikelihood of such a low $\mathrm{MC}$ in recently manufactured and exposed timbers, discontinuous measurements at the lower section of the North face of the panel were also taken, (Figure 9) and indicated average MC levels of $14 \%-16 \%$. The three sensors that registered moisture contents below the detectable limit were therefore excluded from analysis. 

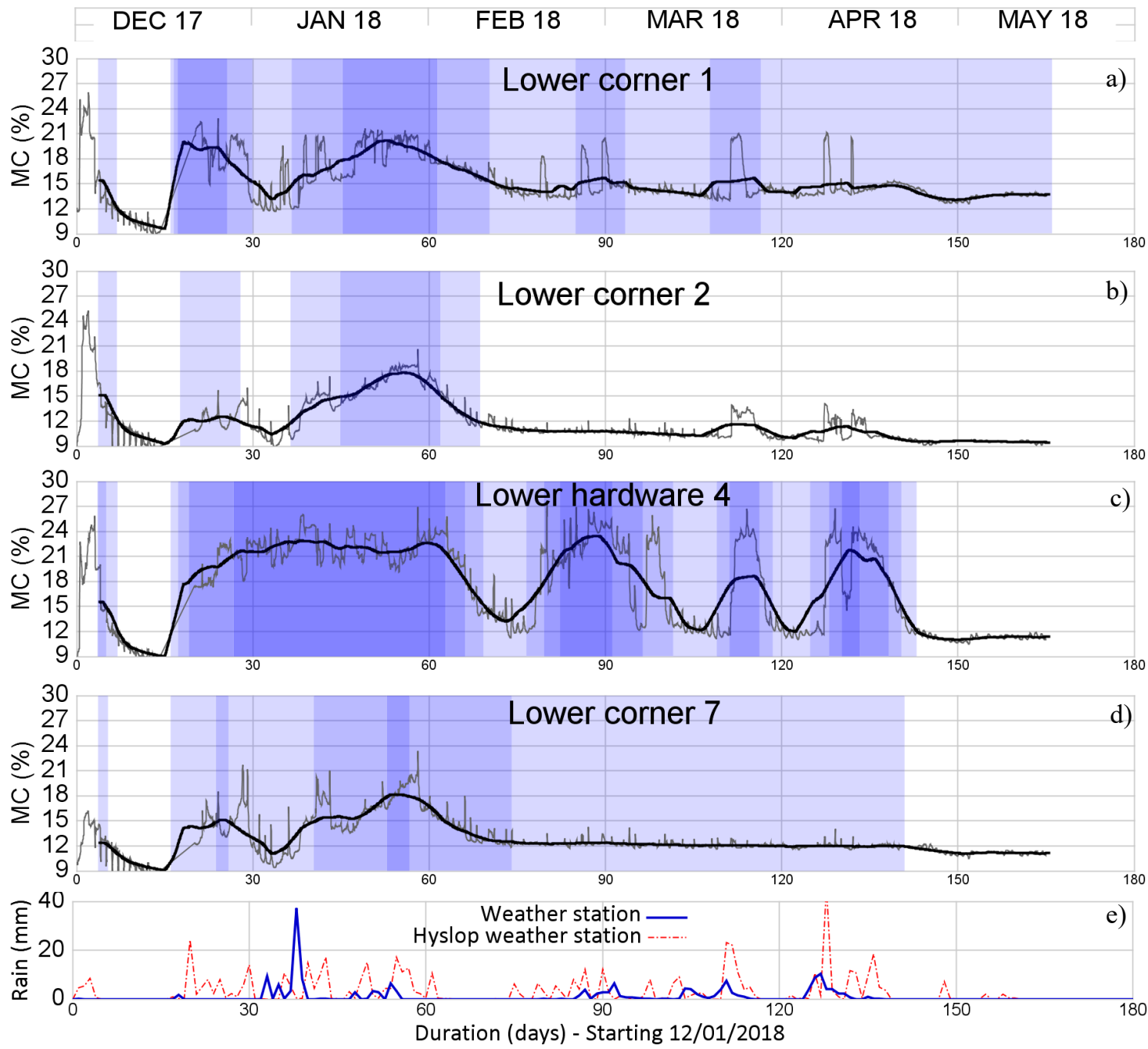

Figure 8. Continuous moisture measurements taken at the lower section of the shear wall. Locations are illustrated in Figure 3b: (a) Lower corner ply 1, (b) lower corner ply 2, (c) lower hardware ply 4, and (d) lower corner ply 7. (e) Rainfall data. Measurements for the first 53 days experienced higher levels of noise due to exposure of the sensors. Raw data is plotted in light grey. An eight-day moving average is depicted with a thick black line. The blue shading overlaying the graph represents tiers of MC growing deeper in hue at $3 \%$ intervals (with $<12 \%$ MC as white). 


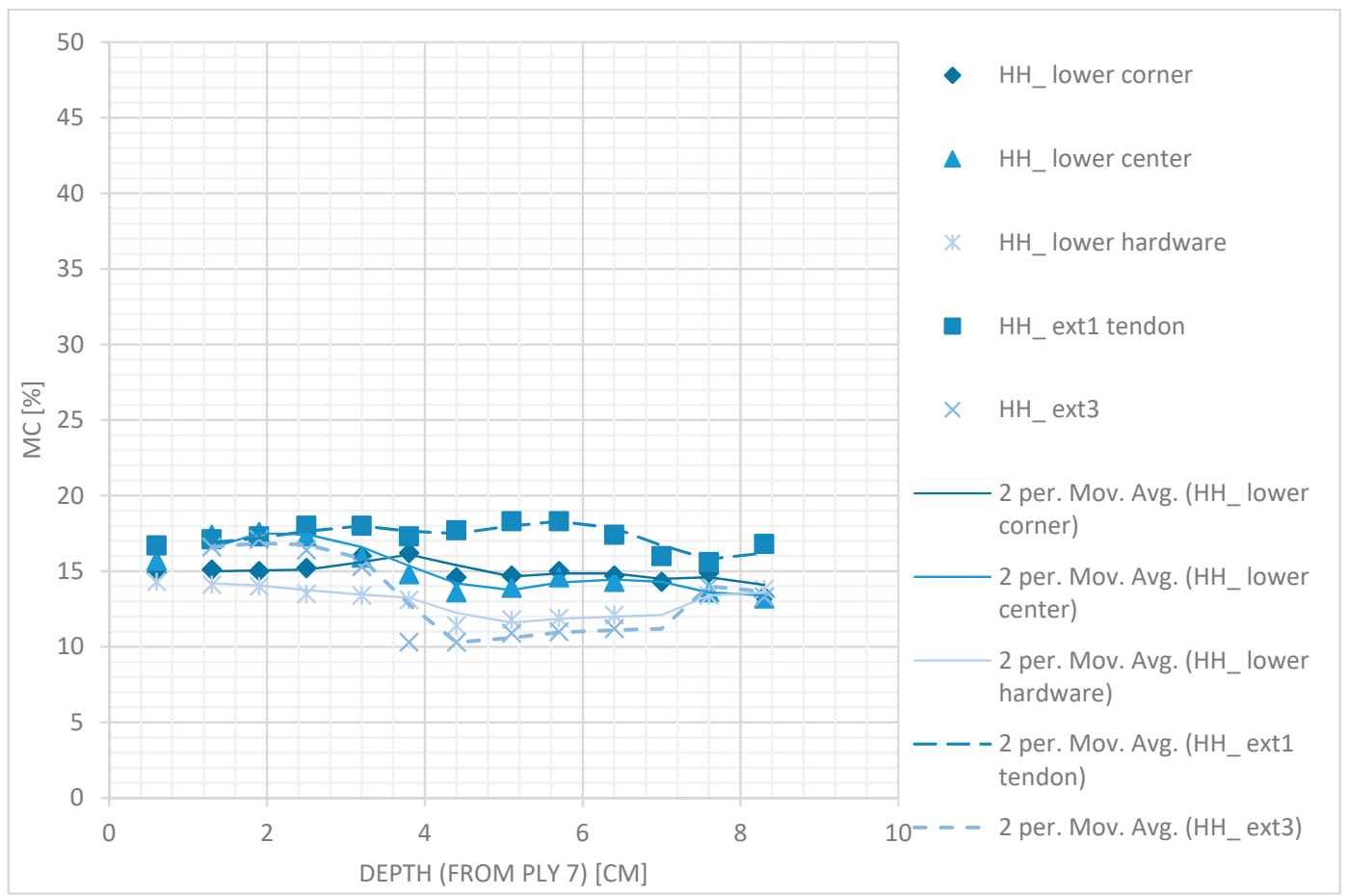

Figure 9. Discontinuous moisture measurements taken at the lower section of the monitored shear wall, from the North face side (continuous lines are moving averages), and of the adjacent, perpendicular shear wall (dashed lines are moving averages). Location depicted in Figure 2. The depth of measurement shows $0.6 \mathrm{~cm}$ increments, from ply 7 to ply 5. Date of measurements: February 92018.

\subsection{CLT floor Moisture Content}

Floor sensors displayed stable behavior until the period between day 110 and 140, when values spiked upwards and remained semi-erratic (Figure 10). The same occurred to a lesser degree between days 147 and 160. The period of erratic behavior corresponds to the enclosure of the monitored detail at its end (exterior enclosure for drying of zone 1) combined with a period of exposure to rain from above (through a large window opening). It was observed that water tended to percolate short distances along the lower face of the CLT floor panels at the interface with the beams, as a result of water pooling at the connection during rain events. Evidence for sensor shorting is strong, since every sensor indicated a coordinated and nearly instantaneous increase in $\mathrm{MC}$ to above fiber saturation levels after enclosure of the details and a large rain event. The bottom-most ply of the floor panel ("Floor 5") in particular continued to show high moisture contents ( $24 \%-30 \%$ range), while the other sensors returned to lower and relatively more stable levels.

Both of the outermost floor plies ("Floor 1" and "Floor 5") showed the greatest levels of moisture gain and loss (Figure 10a,d). The bottom-most ply was the wettest throughout the monitoring period and never dropped below 16\% MC. The uppermost ply ("Floor 1") was also above 16\% MC throughout most of the monitoring period, although it peaked at only $18 \%$ and appeared to dry quickly (e.g., a recorded loss of $2 \%$ MC in just two weeks in February, when conditions were sunny and dry). Plies 2 and 3 ("Floor 2" and "Floor 3") exhibited slower overall wetting rates and lower MCs during wetting events, although moisture content also continued to increase even after some covering and drying (Figure 10b,c). These observations of latent increase at the interior plies were similar to those in previous studies $[11,12,37,38]$. MCs measured at the two glulam beam locations displayed little change over time, remaining around $14 \%+/-1 \%$ MC. "Beam 3," located slightly closer to the moisture trapping interface of the beam and the CLT panel, experienced a slightly higher MC increase (circa $2 \%$ ) than the location in the middle of the beam ("Beam 5") during the stable period of monitoring (days 0-110) (Figure 10e,f). Discontinuous measurements near the floor location (Figure 11) were taken on 
day 71, after a period of good weather and observable drying. These data suggest similar but slightly higher values than continuous measurements at ply 1 (avg. $19.1 \% \mathrm{HH}$ vs. $18 \%$ continuous), ply 2 (avg. $17.6 \% \mathrm{HH}$ vs. $15 \%$ cont.) and ply 3 (avg. $16.6 \% \mathrm{HH}$ vs. $15 \%$ cont.). These differences can be accounted for by a combination of local moisture distributions, which can vary substantially over short distances (less than a $\mathrm{cm}$ ) [11], sensor accuracy $(+/-1 \%)$, as well as slight differences in species and temperature corrections between devices (algorithms and temperature used for correction). Additional discontinuous measurements taken in the CLT panel at the same floor detail, but in the interior of the building (HH_floor_interior) averaged 20.6\% (ply 1), $15.9 \%$ (ply 2) and $16.9 \%$ (ply 3).
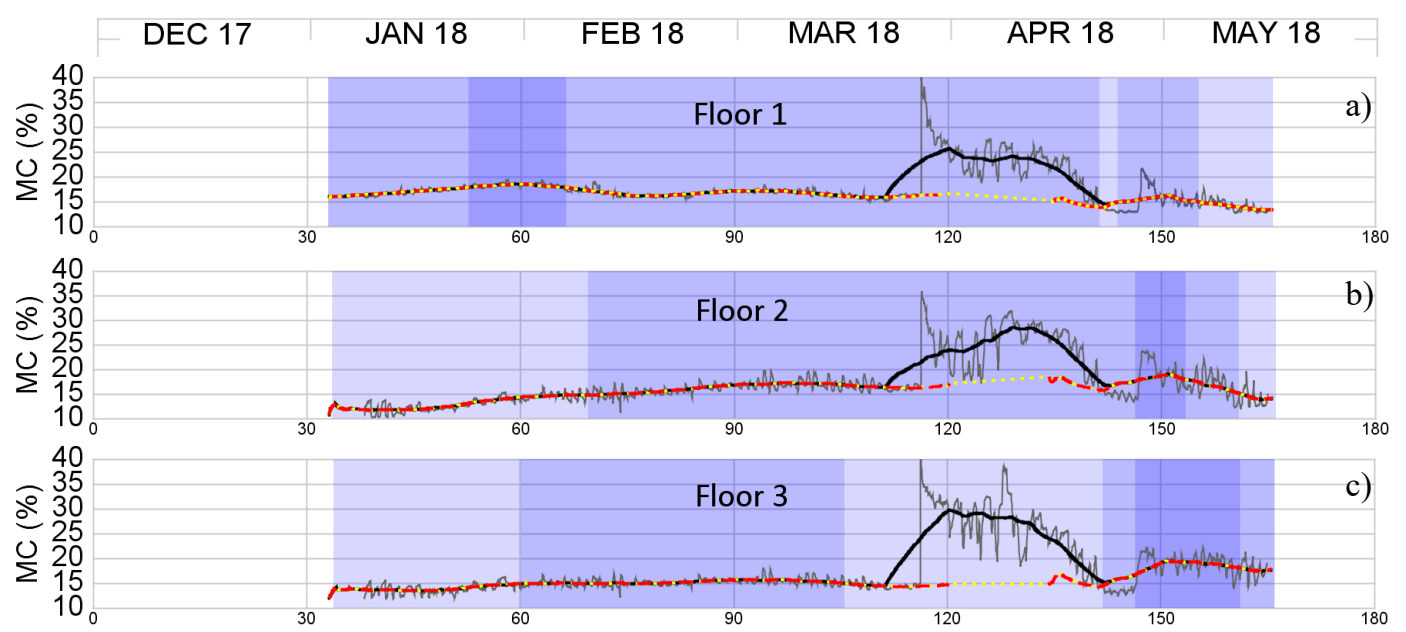

c)
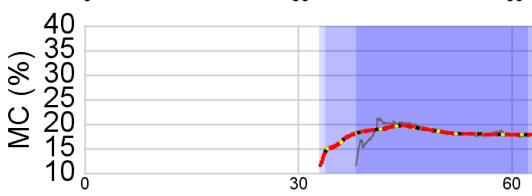

180
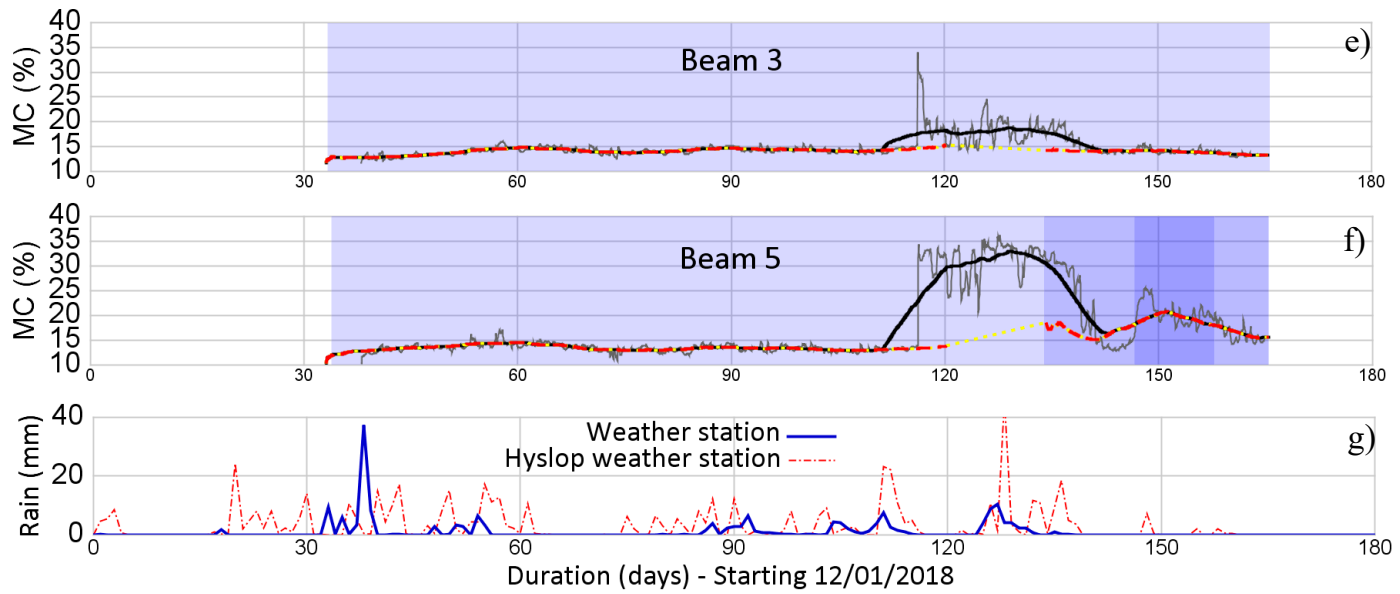

Figure 10. Continuous moisture measurements taken at the floor location. "Floor" indicates readings in the cross laminated timber (CLT) panels, "Beam" in the glulam beam. Progressive numbers in the label indicate the ply reached by the sensor (from the upper-most CLT ply and the external glulam lamina). Locations are illustrated in Figure 4c: MC in the CLT floor panel, (a) ply 1, (b) ply 2, (c) ply 3 , and (d) ply 5. MC in the glulam beam (e) ply 3 and (f) ply 5. (g) Rainfall data. Raw data is plotted in light grey. An eight-day moving average is depicted with a thick black line, while a red dashed line depicts the same moving average with data omitted from the period of highest disturbance (approx. days 110-140). The blue shading overlaying the graph represents tiers of MC-growing deeper in hue at $3 \%$ intervals. 


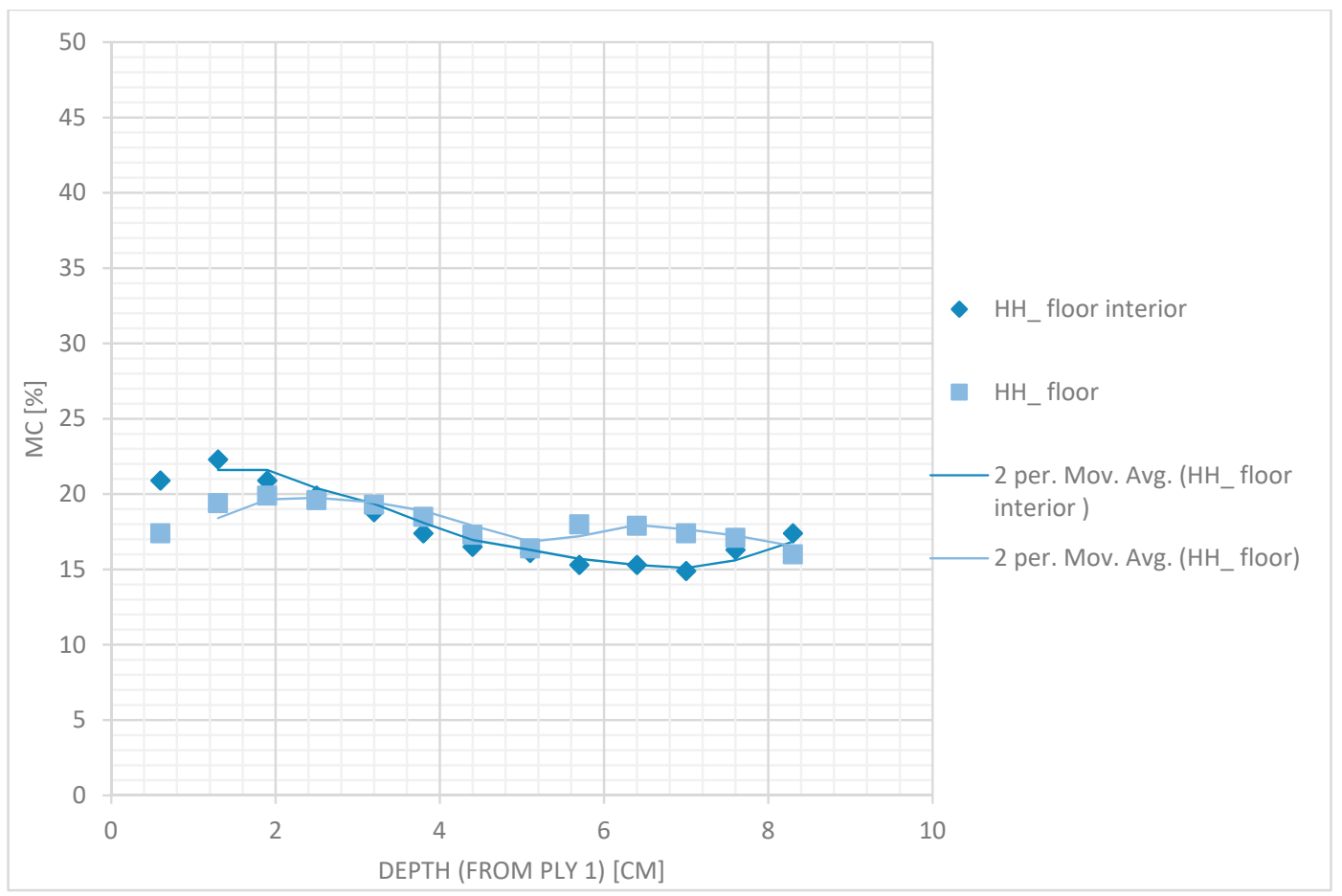

Figure 11. Discontinuous moisture measurements taken at the floor location at different depths in the floor panel with $0.6 \mathrm{~cm}$ increments (from the upper-most surface) close to the continuously monitored points (HH_floor) and at the interior of the building (HH_floor interior). Continuous lines are moving averages. Date of measurements: 9 February 2018.

\section{Discussion and Recommendations}

\subsection{Moisture Content in the CLT Shear Wall and Floor}

The hygrothermal performance of the monitored locations should be interpreted with the understanding that low rainfall and prolonged periods of open structure were unique to this project and allowed for less wetting and more drying than might be standard in a Pacific Northwest oceanic climate. The monitored shear wall was a good representation, however, of the varying conditions and microclimates that can exist on site and define variable hygrothermal behavior. For example, while the northern face was uncoated and shaded from sun, it was also incrementally sheltered from rain during construction by the floor system. The stairwell side, or southern face, on the other hand, was coated, but had no direct physical protection from the elements (sun, wind or rain), during the monitored period, until nearing the completion of the roof. The panel also experienced variable exposure along the E/W axis, according to proximity to the exterior edges of the structure. The highest MCs were observed at the upper east and central sections of the North face, where they often approached or exceeded the fiber saturation point. This was evidently due to the long duration and high degree of rain exposure, combined with the lack of a facially applied weather sealant and solar radiation. MCs at the upper and lower sections of the South face were similar to one another and were generally lower than measurements made at the North face. In addition to low MCs, they also displayed fast drying, indicating that the combination of solar exposure and weather sealant helped mitigate the precipitation-exposure risk. Interestingly, the vertical plies (e.g., 1,3) in these locations also experienced higher MCs and slower drying than the horizontal ones (e.g., 2), with the exception of Lower_corner_7. This may be a result of wicking and/or moisture trapping happening at the upper and lower edges, which were closely set against an impermeable cap and cementitious mortar, respectively. This would be supported by observations of wicking at the base of the adjacent shear wall (HH_ext1_tendon), 
despite the double application of a sealant. The impermeable caps placed at the top of the panels may have also allowed for some condensation and moisture trapping at the top as well.

Upper_tendon_4 (Figure 6c) and Lower_hardware_4 (Figure 8c), showed distinctly higher MC activity than the other continuous measurements. The former sat adjacent to the tendon chase, which could have, in effect, served as a ventilation shaft that would be conducive to maintaining low MC levels. On the other hand, this detail could also be conducive to moisture trapping if the shaft were not well ventilated and/or allowed liquid entry or condensation. Lower_hardware_4 showed large exaggerated fluctuations that closely followed precipitation events and resembled sensor shorting behavior, which coincides with the fact that it is the least sheltered position on the shear wall. A look at the lower moisture contents that the measurements return suggests that this location was likely relatively dry (circa 12\% MC) by day 70 . More observations are needed to assess risk at these types of locations, particularly at the tendon chases.

Discontinuous measurements taken near the bottom of the adjacent shear wall (HH_ext1_tendon) averaged about $2.2 \%, 2.6 \%$, and $2.1 \%$ higher MCs, than averages of those measured in the corresponding depths (ply 7, 6, and 5, respectively) in the lower corner of the monitored shear wall. These were anticipated to be even higher due to the greater exterior exposure and the observed wicking at the cementitious mortar.

MCs in the CLT floor and glulam beam never exceeded fiber saturation, but climbed upwards of $20 \%$ in the outer plies, accumulated at the connection where water could pool and percolate, and decreased slowly compared to the pronounced drying observed in the South face of the shear wall. Handheld measurements taken adjacent to the floor sensors showed MC values that were generally about $2 \%$ higher at each ply. Since resistance type sensors are typically assumed to have a $+/-1 \%-2 \%$ accuracy, it is assumed that this is a result of a combination of sensor error and actual MC distribution. The handheld floor measurements taken at the shaded interior of the structure showed a similar gradient as the southern rain/sun exposed floor location. The beam locations showed excellent resistance to MC gain despite sitting only a few centimeters below the bottom of the floor connection where water was observed to collect. This is further evidence that the sealant and solar exposure had mitigating effects on MC gain.

All considered, the data reinforce the premise that a complex matrix of factors (e.g., sealants, exposure to rain and sun, protection from adjacent assemblies, grain aspect etc.) interactively affect wetting and drying at a given location, leading to highly variable MC distributions. In general, the hygrothermal data indicate that (1) solar exposure combined with facial weather coating (in addition to edge sealing), and/or incrementally shielding timbers with floor assemblies had positive effects in terms of mitigating MC gain, and (2) edge-sealed (but not facially sealed) CLT can be critically at-risk to prolonged fiber saturation and moisture accrual at every layer after only a few months of outdoor exposure, particularly when shaded from the sun but not the rain. Solar radiation may play a major role in the development of a moisture gradient through the thickness of the panel, which is supported by the observed rapid drying in the southern-facing plies and moisture contents at the exposed floor location when compared to the interior.

\subsection{Moisture Mitigation Considerations for Design and Construction}

As there are still unknowns regarding the hygrothermal behavior of mass timber buildings and their assemblies-particularly US made CLT in a Pacific NW climate-it is important to err on the conservative side in terms of protection strategies during design and construction. The two primary strategies are (1) near-total elimination of risk and (2) prevention, mitigation and potential remediation. The strategy of near-total elimination of exposure are observed in some European projects, such as Limnologen (Sweden) [53], and the ETH House of Natural Resources (Switzerland) [29], where canopies were erected over the entire structures during erection. The benefits of such a strategy include that issues related to weathering during construction (e.g. safety, aesthetic degradation, etc.) will be, generally, avoided altogether, thus reducing variables and potentially costly remediation efforts. 
Such measures would also lead to a drier, safer, and more efficient construction site, eliminating the need to spend time on mitigation efforts (such as tarping, shedding water, etc.). The full-enclosure strategy would need to be considered under a long-term cost benefit analysis, weighing prevention/mitigation costs (e.g., coating panels, construction time, etc.) and risk against the high up front cost and logistical considerations.

One simple preventative strategy would be to slate the erection of mass timber buildings entirely during the dry season with the guarantee of enclosure before a wet season. Such a narrow window would highly limit design and construction flexibility, however. On the other hand, since the erection of a mass timber superstructure can be very rapid, particularly with a simplified layout, there is a lot of potential for exposure prevention by utilizing prefabricated exterior wall assemblies that are ready to install at delivery, as seen at Brock Commons [31,32]. At the Forest Science Complex, high levels of moisture were observed at certain unsealed areas. The presence of vapor permeable coatings on the timber elements appeared to be effective in terms of mitigating moisture, though they cannot be exclusively relied upon as a strategy, as wicking and moisture gains were still observed in sealed elements. Defining vulnerable areas to exposure during construction (e.g., based on duration and degree of exposure) and sealing only those regions, may be a cost-effective strategy to improve moisture resistance of the elements on site.

Combining a refined coating strategy with moisture-conscious detailing would be a highly effective general strategy, at least in terms of preventing the high levels of moisture accumulation seen in elements that were uncoated or prone to moisture trapping. Detailing should strive to minimize close contact between porous materials (particularly at end grain) and general conditions that foster moisture trapping or pooling. Design of details should also consider the importance of avoiding moisture trapping during construction, as well as in service. The ' $4 \mathrm{D}$ 's rule' recommended moisture detailing (distance, deflection, drainage and drying) [54] should be applied also for moisture management during construction. This may entail shielding hardware from above or allowing for drainage, and/or generally spacing elements so that air can circulate. Assemblies should always be designed so that they are allowed to dry in service to avoid built-in moisture.

\subsection{Data analysis and Hygrothermal Monitoring Considerations}

While the objective of construction monitoring was to elicit the hygrothermal performance of mass timber elements during exposure, it also served as an educational tool that allowed to iteratively assess and augment the overarching monitoring plan and methodology (e.g., sampling criteria, installation methods and data analysis). This highlights the need for more hygrothermal data from similar structures, a larger focus on methodology as a research objective, and the development of a general methodological protocol. Since moisture distribution can vary based on temporal-spatial factors, a protocol should aim to define an ideal balance between diversity and redundancy in sensor locations, thus allowing for a more global and statistically significant data set.

Observed sources of variability in the monitored data include (1) building microclimates (variable exposure due to, e.g., predominant solar and wind orientation); (2) system microclimates (e.g., self-sheltering of some areas of the structure by others); (3) assembly details (e.g., spatial orientation, moisture trapping conditions, etc.); (4) materiality (e.g., variability in wood, sub-assembly type-e.g., CLT-, and surface treatments).

The sensors installed during the construction phase of the Forest Science Complex represent only a fraction of the full hygrothermal monitoring plan (19 of 250 locations), and thus the current data do not reflect an average performance of the structure or its components. While it would be advantageous to install more sensors during construction, it is logistically easier to install equipment at a later phase. This is because installation during transport or early phases of construction involves higher levels of coordination and greatly increases the odds of physically damaging sensors [33]. As observed in this and other studies, environmental exposure during construction also appears to be a risk in terms of influencing or damaging sensors, thus additional precautions should be taken in order to protect them. 
More research is needed aimed at systematically eliciting the influence that environmental factors have on resistance readings instrumentation and selection of the most appropriate type of installation depending on the application.

Developing a database of hygrothermal trends that are correlated to exposure, assembly, and location conditions (e.g., distance from edges and depth in wood) would provide a basis for models that could help reference sensor reliability. This will support the development of harmonized procedures for post-processing of MC data and data representation. Data processing is indeed crucial to deliver clear and useful information to decision-makers in charge of the service life management of the monitored or similar structures. In this study, moving average and erroneous data omission were applied to improve data readability. Further efforts will be dedicated to automatize this procedure and support long-term usability of the monitoring system.

\section{Conclusions}

This study explores moisture performance of US-manufactured mass timber exposed to the Northwest Pacific climate during construction. Moisture was monitored at a CLT shear wall and a floor connection during the construction phase of the new Forest Science Complex at Oregon State University. In total, 19 permanent MC sensors were installed, which represent less than $10 \%$ of the sensors that will eventually be placed in the building. Limitations in this study are the limited number of structural systems monitored during construction, the known variability of the wood material, as well as the variability of a building's microclimate conditions. Knowing these limitations, sampling criteria were chosen to capture a variety of detail and material conditions. Additional discontinuous measurements were used to validate results, as well as to probe locations that appeared vulnerable.

This work represents the first in-field evaluation of the hygrothermal response of CLT shear walls (featuring a post-tensioning self-centering system) providing valuable information regarding potential points of moisture vulnerability, to be considered for water control during construction, as well as for preventative strategies at the manufacturing and design levels. This work also represents one of only a few studies observing a general moisture response of CLT to wet construction conditions.

Due to a mild winter and construction delays that results in a prolonged state of covered but open-structure, wetting and drying were less and more pronounced, respectively, than might be typical in this type of construction in the Pacific Northwest climate.

Very high moisture levels were recorded at uncoated, shaded elements and at moisture trapping connections, whereas conditions at lower risk of high and prolonged wetting were where (1) partial shelter was provided (e.g., by the floors); (2) faces were coated with a vapor permeable sealant; and (3) prospect favored solar exposure. With this knowledge, better prevention strategies can be developed at the design and construction levels, improving the service life of such structures. These results reify the premise that hygrothermal performance will greatly vary according to environmental and building, assembly, and material variables. This variability and the potential of a reduced availability of monitoring data from those planned (i.e., risk of losing the signal or erroneous readings) confirm the need of some redundancy in the planned installation to capture the true performance of a structure. More hygrothermal monitoring projects will allow to develop more refined sampling criteria that will in turn help to define moisture-sensitive members and details in structures.

Finally, moisture data during construction are critical to develop and apply models for service life prediction and management of mass timber products and novel engineering systems. As the first building featuring post-tensioned rocking CLT shear walls (and the first one using a post-tensioned timber system in North America) the Forest Science Complex offers a unique opportunity to evaluate the performance of this system. Monitoring data in the shear wall will be used to analyze (and predict) post-tensioning losses as affected by mechano-sorptive creep and shrinkage in the timber material.

Author Contributions: Conceptualization M.R.; Methodology, M.R. and E.S.; Validation, M.R.; Formal Analysis, E.S.; Investigation, M.R. and E.S.; Resources, M.R.; Data Curation, M.R. and E.S.; Writing-Original Draft Preparation, 
E.S.; Writing-Review \& Editing, M.R.; Visualization, E.S.; Supervision, M.R.; Project Administration, M.R.; Funding Acquisition, M.R.

Funding: This study is part of the Living Lab @ Peavy Hall project, conducted through the TallWood Design Institute with funding by the U.S. Department of Agriculture's Agricultural Research Service (USDA ARS Agreement No. 58-0202-5-001). The material presented in this contribution is also based upon work that is supported by the National Institute of Food and Agriculture, U.S. Department of Agriculture, McIntire Stennis project under 1009740.

Acknowledgments: Authors are grateful to Michael Green Architecture (MGA), Andersen Construction and SMT Research for their collaboration.

Conflicts of Interest: The authors declare no conflict of interest.

\section{References}

1. Pei, S.; Rammer, D.; Popovski, M.; Williamson, T.; Line, P.; van de Lindt, J.W. An overview of CLT Research and Implementation in North America. In Proceedings of the WCTE 2016, Vienna, Austria, 22-25 August 2016.

2. Gasparri, E.; Lucchini, A.; Mantegazza, G.; Mazzucchelli, E.S. Construction management for tall CLT buildings: From partial to total prefabrication of façade elements. Wood Mater. Sci. Eng. 2015, 10, $256-275$. [CrossRef]

3. Finnish Standards Association. Execution of Timber Structures, Rules for Load-Bearing Structures of Buildings; Finnish Standards Association, Confederation of Finnish Construction Industries RT: Helsinki, Finland, 2012.

4. DIN 68800: 2012. Wood preservation-Part 2: Preventive Constructional Measures in Buildings; German Institute for Standardisation (Deutsches Institut für Normung), Beuth Verlad: Berlin, Germany, 2012.

5. Wang, J. Guide for On-Site Moisture Management of Wood Construction; FPInnovations: Pointe-Claire, QC, Canada, 2016.

6. Wang, J.W.; Stirling, R.; Morris, P.I.; Taylor, A.; Lloyd, J.; Kirker, G.; Lebow, S.; Mankowski, M.E.; Barnes, H.M.; Morrell, J.J. Durability of mass timber structures: A review of the biological risks. Wood Fiber Sci. 2018, 50, 110-127. [CrossRef]

7. Viitanen, H. Factors Affecting the Development of Mould and Brown Rot Decay in Wooden Material and Wooden Structures. Effect of Humidity, Temperature and Exposure Time. Ph.D. Thesis, University of Uppsala, Uppsala, Sweden, 1996.

8. Viitanen, H.; Vinha, J.; Salminen, K.; Ojanen, T.; Peuhkuri, R.; Paajanen, L. Moisture and bio-deterioration risk of building materials and structures. J. Build. Phys. 2010, 33, 201-224. [CrossRef]

9. Isaksson, T.; Brischke, C.; Thelandersson, S. Development of decay performance models for outdoor timber structures. Mater. Struct. 2012, 46, 1209-1225. [CrossRef]

10. Gülzow, A.; Richter, K.; Steiger, R. Influence of wood moisture content on bending and shear stiffness of cross laminated timber panels. Eur. J. Wood Wood Prod. 2011, 69, 193-197. [CrossRef]

11. Schmidt, E.L.; Riggio, M.; Barbosa, A.R.; Mugabo, I. Environmental response of a CLT floor panel: Lessons for moisture management and monitoring of mass timber buildings. Build. Environ. 2019, 148, 609-622. [CrossRef]

12. Schmidt, E.; Riggio, M.; Laleicke, P.F.; Barbosa, A.; van den Wymelenberg, K. How monitoring CLT buildings can remove market barriers and support designers in North America: An introduction to preliminary environmental studies. Rev. Port. Eng. Estrut. 2018, 7, 41-48.

13. Nairn, J.A. Cross laminated timber properties including effects of non-glued edges and additional cracks. Eur. J. Wood Wood Prod. 2017, 75, 973-983. [CrossRef]

14. Gamper, A.; Dietsch, P.; Merk, M.; Winter, S. Building Climate-Long-term measurements to determine the effect on the moisture gradient in large-span timber structures|Gebudeklima-Langzeitmessung zur Bestimmung der Auswirkungen auf Feuchtegradienten in Holzbauteilen. Bautechnik 2013, 90, 508-519. [CrossRef]

15. Niklewski, J.; Isaksson, T.; Hansson, E.F.; Thelandersson, S. Moisture conditions of rain-exposed glue-laminated timber members: The effect of different detailing. Wood Mater. Sci. Eng. 2018, 13, 129-140. [CrossRef]

16. Grossman, P.U.A. Requirements for a model that exhibits mechano-sorptive behavior. Wood Sci. Technol. 1976, 10, 163-168. [CrossRef] 
17. Holzer, S.M.; Loferski, J.R.; Dillard, D.A. A review of creep in wood: Concepts relevant to develop long-term behavior predictions for wood structures. Wood Fiber Sci. 1989, 21, 376-392.

18. Granello, G.; Leyder, C.; Palermo, A.; Frangi, A.; Pampanin, S. Design Approach to Predict Post-Tensioning Losses in Post-Tensioned Timber Frames. J. Struct. Eng. 2018, 144, 04018115. [CrossRef]

19. Nguyen, T.T.; Dao, T.N.; Aaleti, S.; Hossain, K.; Fridley, K.J. Numerical Model for Creep Behavior of Axially Loaded CLT Panels. J. Struct. Eng. 2019, 145, 04018224. [CrossRef]

20. D'Ayala, D.; Aktas, Y.D. Moisture dynamics in the masonry fabric of historic buildings subjected to wind-driven rain and flooding. Build. Environ. 2016, 104, 208-220. [CrossRef]

21. Dedesko, S.; Siegel, J.A. Moisture parameters and fungal communities associated with gypsum drywall in buildings. Microbiome 2015, 3, 71. [CrossRef] [PubMed]

22. Bedon, C. Diagnostic analysis and dynamic identification of a glass suspension footbridge via on-site vibration experiments and FE numerical modelling. Compos. Struct. 2019, 216, 355-378. [CrossRef]

23. Marques, L.F.R.L.; Lourenço, P.B.; de Roeck, G.; Campos-Costa, A.; Roque, J. Monitoring historical masonry structures with operational modal analysis: Two case studies. Mech. Syst. Signal Process. 2010, 24, 1291-1305.

24. Tannert, T.; Berger, R.; Müller, A. Remote moisture monitoring of timber bridges: A case study. In Proceedings of the 5th International Conference on Structural Health Monitoring of Intelligent Infrastructure (SHMII-5) 2011, Cancun, Mexico, 11-15 December 2011; pp. 1-9.

25. Björngrim, N.; Hagman, O.; Wang, X.A. Moisture content monitoring of a timber footbridge. BioResources 2016, 11, 3904-3913. [CrossRef]

26. Koch, J.; Simon, A.; Arndt, R.W. Monitoring of Moisture Content of Protected Timber Bridges. In Proceedings of the WCTE 2016 World Conference Timber Engineering, Vienna, Austria, 22-25 August 2016.

27. Sorin, E.; Lanata, F.; Boudaud, C. Behaviour of Timber Structures Under Variable Environment Through Long-Term Monitoring. In Proceedings of the WCTE 2016 World Conference Timber Engineering, Vienna, Austria, 22-25 August 2016.

28. Jorge, L.; Dias, A.; Costa, R. Performance of X-Lam panels in a sports center with an indoor swimming-pool. J. Civ. Struct. Health Monit. 2015, 5, 129-139. [CrossRef]

29. Leyder, A.F.C.; Chatzi, E. Structural health monitoring of an innovative timber structure. In Proceedings of the Second International Conference on Performance-Based and Life-Cycle Structural Engineering, Brisbane, Australia, 9-11 December 2015; Volume 6, No. 0974. pp. 102-108.

30. Wang, J.; Karsh, E.; Finch, G.; Chen, M. Field Measurement of Vertical Movement and Roof Moisture Performance of the Wood Innovation and Design Centre. In Proceedings of the WCTE 2016 World Conference Timber Engineering, Vienna, Austria, 22-25 August 2016; No. Lvl. pp. 2-3.

31. Mustapha, G.; Khondoker, K.; Higgins, J. Moisture Performance and Vertical Movement Monitoring of Pre-Fabricated Cross Laminate Timber-Featured Case Study: Ubc Tallwood House. In Proceedings of the 15th Canadian Conference on Building Science and Technology, Vancouver, BC, Canada, 6-8 November 2017; pp. 1-15.

32. Mustapha, G.; Khondoker, K. Structural performance monitoring technology and data visualization tools and techniques-Featured case study: UBC Tallwood House. In Proceedings of the 1st International Conference on New Horizons in Green Civil Engineering, Victoria, BC, Canada, 25-27 April 2018.

33. Kordziel, S. Study of Moisture Conditions in a Multi-Storey Mass Timber Building Through the Use of Sensors and WUFI Hygrothermal Modeling. Master's Thesis, Colorado School of Mines, Golden, CO, USA, 2017.

34. Zelinka, S.; Kordziel, S.; Pei, S.; Glass, S.V.; Tabares-Velasco, P.C. Moisture monitoring throughout the construction and occupancy of mass timber buildings. In Proceedings of the 1st International Conference on New Horizons in Green Civil Engineering, Victoria, BC, Canada, 25-27 April 2018; No. 3. pp. 25-28.

35. Alsayegh, G.; Mukhopadhyaya, P.; Wang, J.; Zalok, E.; van Reenen, D. Preliminary Characterization of Physical Properties of Cross-Laminated-Timber (CLT) Panels for Hygrothermal Modelling. Adv. Civ. Eng. Mater. 2013, 2, 472-484. [CrossRef]

36. Lepage, R. Moisture Response of Wall Assemblies of Cross-Laminated Timber Construction in Cold Canadian Climates. Master's Thesis, University Waterloo, Waterloo, ON, Canada, 2012; p. 139.

37. McClung, R.; Ge, H.; Straube, J.; Wang, J. Hygrothermal performance of cross-laminated timber wall assemblies with built-in moisture: Field measurements and simulations. Build. Environ. 2014, 71, 95-110. [CrossRef] 
38. Wang, J. Wetting and Drying Performance of Wood-Based Assemblies Related to On-Site Moisture Management. In Proceedings of the WCTE 2016 World Conference Timber Engineering, Vienna, Austria, 22-25 August 2016; No. 2. pp. 1-22.

39. Lepage, R.; Finch, G. Moisture uptake testing for CLT floor panels in a tall wood building in Vancouver. In Proceedings of the 15th Canadian Conference on Building Science and Technology, Vancouver, BC, Canada, 6-8 November 2017; No. Mc. pp. 1-17.

40. Sarti, F.; Palermo, A.; Pampanin, S. Simplified design procedures for post-tensioned seismic resistant timber walls. In Proceedings of the 15th WCEE, Lisbon, Portugal, 24-28 September 2012.

41. van de Lindt, J.W.; Furley, J.; Aminic, M.O.; Pei, S.; Tamagnone, G.; Barbosa, A.R.; Rammer, D.; Line, P.; Fragiacomo, M.; Popovski, M. Experimental seismic behavior of a two-story CLT platform building. Eng. Struct. 2019, 183, 408-422. [CrossRef]

42. Ortiz, E. Mass Plywood Panels: Designing with the Newest Mass Timber Structural Product. Available online: http://www.woodworks.org/wp-content/uploads/presentation_slides-ORTIZ-Mass-Plywood-PanelsWSF-180425.pdf (accessed on 24 September 2018).

43. Riggio, M.; Alhariri, N.; Hansen, E. Paths of innovation and knowledge management in timber construction in North America: A focus on water control design strategies in CLT building enclosures. Archit. Eng. Des. Manag. 2019. [CrossRef]

44. Dietsch, P.; Franke, S.; Franke, B.; Gamper, A.; Winter, S. Methods to determine wood moisture content and their applicability in monitoring concepts. J. Civ. Struct. Health Monit. 2014, 5, 115-127. [CrossRef]

45. Hyslop Weather Station Archives. Available online: https://agsci.oregonstate.edu/corvallis-farm-unit/ weather/weather-data (accessed on 5 June 2018).

46. American National Standard/The Engineered Wood Association. Standard for Performance-Rated Cross-Laminated Timber; ANSI/APA PRG 320-2018; American Psychological Association: New York, NY, USA, 2018.

47. Wengert, G.; Bois, P. Evaluation of electric moisture meters on kiln-dried lumber. For. Prod. J. 1997, 47, 60-62.

48. Wilson, P. Accuracy of a capacitance-type and three resistance-type pin meters for measuring wood moisture content. For. Prod. J. 1999, 49, 29-32.

49. James, W.L. Electric Moisture Meters for Wood; USDA-FS FPL-GTR-6; U.S. Department of Agriculture, Forest Service, Forest Products Laboratory: Madison, WI, USA, 1988.

50. Riggio, M.; Anthony, R.W.; Augelli, F.; Kasal, B.; Lechner, T.; Muller, W.; Tannert, T. In Situ assessment of structural timber using non-destructive techniques. Mater. Struct. 2014, 47, 749-766. [CrossRef]

51. Sandberg, K.; Pousette, A. Moisture Conditions in Coated Glulam Beams and Columns During Weathering. In Proceedings of the International Conference on Durability of Building Materials and Components, Porto, Portugal, 12-15 April 2011; pp. 1-8.

52. Eugene: Monthly and Annual Climate. Administration, National Oceanic and Atmospheric. Available online: https://www.wrh.noaa.gov/pqr/eugclimate/pg67.pdf (accessed on 5 June 2018).

53. Serrano, E. Limnologen-Experiences from an 8-Storey Timber Building Limnologen Potpourri-Praktische Erfahrungen von Immeubles en Bois de Huit Étages; Internationales Holzbau-Forum: Garmisch, Germany, 2009; pp. 1-12.

54. Beebe, K.; Kam-Biron, M. Five Ds of Moisture Management: Deflection, Drainage, Drying, Distance, and Durable Materials. In Proceedings of the SEAC 2016, Montpellier, France, 21-22 October 2016.

(C) 2019 by the authors. Licensee MDPI, Basel, Switzerland. This article is an open access article distributed under the terms and conditions of the Creative Commons Attribution (CC BY) license (http://creativecommons.org/licenses/by/4.0/). 